\title{
GABA Shapes Sensitivity to Interaural Intensity Disparities in the Mustache Bat's Inferior Colliculus: Implications for Encoding Sound Location
}

\author{
Thomas J. Park and George D. Pollak \\ Department of Zoology, University of Texas at Austin, Austin, Texas 78712
}

This study examined how GABAergic inhibition affected binaural properties of neurons in the mustache bat's inferior colliculus. Evaluations were made by documenting changes in acoustically evoked inhibition that occurred when GABAergic inputs were reversibly blocked by lontophoretic application of the GABA $_{A}$ antagonist bicuculline. We studied neurons sensitive to interaural intensity disparities (IIDs), since these are the principal cues animals use to localize high-frequency sounds. Neurons sensitive to these cues receive excitation from one ear and inhibition from the other ear, and are called EI neurons. Recordings focused on the El region in the hypertrophied $60 \mathrm{kHz}$ isofrequency contour, where the sensitivities of the El cells to IIDs are systematically ordered, thereby creating a map of IID sensitivity. EI neurons were classified on the basis of their IID functions, of which there were two principal types. Seventy percent of the cells had conventional IID functions where the firing rate evoked by a fixed intensity at the contralateral (excitatory) ear remained constant with low intensities at the ipsilateral (inhibitory) ear and then declined progressively as the intensity at the ipsilateral ear increased. We refer to cells that had this type of IID function simply as EI neurons. The IID functions in the remaining $30 \%$ of the cells showed binaural facilitation and were classified as EI/f neurons. In these cells, increasing sound intensity at the ipsilateral (inhibitory) ear when the intensity at the contralateral (excitatory) ear was fixed, initially caused the firing rate to increase by at least $25 \%$ above the rate evoked by the sound at the contralateral ear alone. Additional intensity increases at the ipsilateral ear then resulted in a marked decline in response rate.

We examined the effects of bicuculline on three binaural properties: (1) the degree of inhibition evoked by the ipsilateral ear (the maximum inhibition), (2) the IID at which the unit's discharge rate declined by $50 \%$ (the $50 \%$ point), and (3) binaural facilitation. There are three main findings. First, bicuculline substantially reduced or eliminated the inhibition

Received Aug. 26, 1992; revised Nov. 12, 1992; accepted Nov. 16, 1992.

We thank Carl Resler for designing and implementing the electronics and computer programs, without which this study could not have been conducted. We also thank Don Caspary for instructing us in the techniques of microiontophoresis. We thank Nick Fuzessery, Benedikt Grothe, Nancy Markovitz, Carl Resler, Dan Sanes, Wesley Thompson, Pedro Weisleder, Jeffrey Wenstrup, and Lenny Yang for their comments on the manuscript. This work was supported by NIH Grant DC 20068.

Correspondence should be addressed to Dr. Thomas J. Park at above address. Copyright (C) 1993 Society for Neuroscience $0270-6474 / 93 / 132050-18 \$ 05.00 / 0$ evoked by the ipsilateral ear in about $40 \%$ of the cells. In the other $60 \%$ of the cells, bicuculline had little or no effect on the magnitude of the ipsilaterally evoked inhibition. The second finding is that in more than half of the cells in which there was little or no reduction in the magnitude of the ipsilaterally evoked inhibition, bicuculline changed the IID at which the ipsilaterally evoked inhibition caused the discharge rate to decline by $\mathbf{5 0 \%}$. In most cells, a more intense signal at the ipsilateral ear was required to produce the criterion inhibition with bicuculline than in the predrug condition. The third finding is that bicuculline affected binaural facilitation in $\mathbf{8 0} \%$ of $\mathrm{El} / \mathrm{f}$ cells, and in more than half of the EI/f cells bicuculline totally eliminated the facilitation.

One implication of the present study is that the collicular map of IID sensitivity is formed to a substantial degree in the colliculus by GABAergic innervation that likely originates in the dorsal nuclei of the lateral lemniscus. The GABAergic innervation contributes to the establishment of the map in at least three ways. The first is by the creation of the EI properties in some collicular cells through the convergence of excitatory and GABAergic inhibitory inputs. This not only establishes the maximum inhibition of the cell, but also establishes the cell's $50 \%$ point. A second way occurs in other cells where GABAergic inputs adjust $50 \%$ points and thus adjusts the neuron's sensitivity to IIDs. A third way occurs in yet other cells in which the inhibition produced by inputs from the ipsilateral ear was increased. Another implication of this study is that GABAergic inhibition within the colliculus appears to create or reinforce binaural facilitation in most collicular El/f cells.

IKey words: GABA, changes in binaural properties, inferior colliculus, mustache bat, interaural intensity disparity, inhibition]

Interaural intensity disparities (IIDs) are important cues for localizing high-frequency sounds (Erulkar, 1972; Mills, 1972). The intensity disparities are generated by the shadowing of the head and ears and by the directional properties of the pinnae. The information from the two ears is conveyed into the CNS, where it is compared by binaural neurons. The comparison is a subtractive process whereby signals from one ear excite and signals from the other ear inhibit the binaural cells. These socalled excitatory/inhibitory cells are sensitive to intensity disparities and express the comparison of IIDs in their firing rates (e.g., Aitkin, 1986; Irvine, 1986; Pollak and Casseday, 1989).

The projection system associated with excitatory/inhibitory properties originates in the lateral superior olive, the lowest 
nucleus that receives converging inputs from the two ears and where excitatory/inhibitory neurons are initially formed (Boudreau and Tsuchitani, 1968; Goldberg and Brown, 1968, 1969; Caird and Klinke, 1983; Moore and Caspary, 1983; Cant and Morest, 1984; Harnischfeger et al., 1985; Cant and Casseday, 1986; Sanes and Rubcl, 1988; Covey et al., 1991). Figure 1 shows the components of the excitatory/inhibitory pathway that project to the inferior colliculus. The lateral superior olive projects bilaterally to the inferior colliculus and to the dorsal nucleus of the lateral lemniscus, both of which have large populations of excitatory/inhibitory neurons (Brugge et al., 1970; Roth et al., 1978; Brunso-Bechtold et al., 1981; Glendenning et al., 1981, 1992; Aitkin, 1986; Shneiderman and Henkel, 1987; Ross et al., 1988; Covey and Casseday, 1991). The dorsal nucleus of the lateral lemniscus, in turn, also sends bilateral projections to the inferior colliculus (Goldberg and Moore, 1967; BrunsoBechtold et al., 1981; Kudo, 1981; Zook and Casseday, 1987; Ross et al., 1988; Shneiderman et al., 1988; Frisina et al., 1989; Ross and Pollak, 1989; Shneiderman and Oliver, 1989), thereby completing the excitatory/inhibitory pathway to the midbrain.

It has been generally assumed that the excitatory/inhibitory features of ncurons in the lateral superior olive are relayed directly to the inferior colliculus (Fig. 1). Consistent with this idea are recent studies that suggest that the crossed projection from the lateral superior olive to the inferior colliculus is excitatory (Saint Marie et al., 1989; Saint Marie and Baker, 1990; Park et al., 1991; Glendenning et al., 1992). However, studies by several investigators (Faingold et al., 1989, 1991; Li and Kelly, 1992a,b; Pollak et al., 1992; Sally and Kelly, 1992) also suggest that there may be a second way that excitatory/inhibitory response properties are established in collicular cells, namely, that the excitatory/inhibitory properties are created in the colliculus itself by the convergence of excitatory inputs evoked by the contralateral ear and inhibitory inputs evoked by the ipsilateral ear.

Recent immunocytochemical studies show that two major pathways could provide the colliculus with ipsilaterally evoked inhibition (Fig. 1). The first is the uncrossed projection from the lateral superior olive, which is largely glycinergic and thus likely to be inhibitory (Hutson et al., 1987; Saint Marie et al., 1989; Saint Marie and Baker, 1990; Park et al., 1991; Glendenning et al., 1992). The second is from the contralateral dorsal nucleus of the lateral lemniscus, a nucleus whose cells are predominantly GABAergic (Adams and Mugniani, 1984; Mugniani and Oertel, 1985; Thompson et al., 1985; Roberts and Ribak, 1987a,b; Larue et al., 1991; Pollak et al., 1992; Vater et al., 1992) and which sends a large projection to the inferior colliculus (Ross et al., 1988; Shneiderman and Oliver, 1989). Both of these inhibitory projections should be excited by sounds delivered to the ear ipsilateral to the inferior colliculus (Fig. 1).

The goal of the present study was to evaluate the role of GABAergic inputs in shaping the binaural properties of excitatory/inhibitory neurons in the inferior colliculus. The role of glycinergic inputs will be considered in a future report. Evaluations were made by documenting changes in acoustically evoked inhibition that occurred when GABAergic inputs were reversibly blocked by iontophoretic application of the $\mathrm{GABA}_{\mathrm{A}}$ antagonist bicuculline (Cooper et al., 1982; Borman, 1988). The rationale is that if excitatory/inhibitory properties are created in the colliculus by the convergence of excitatory and GABAergic inhibitory inputs, then removing the influence of those inhibitory inputs should reduce or eliminatc the acoustically evoked inhibition. On the other hand, if excitatory/inhibitory response

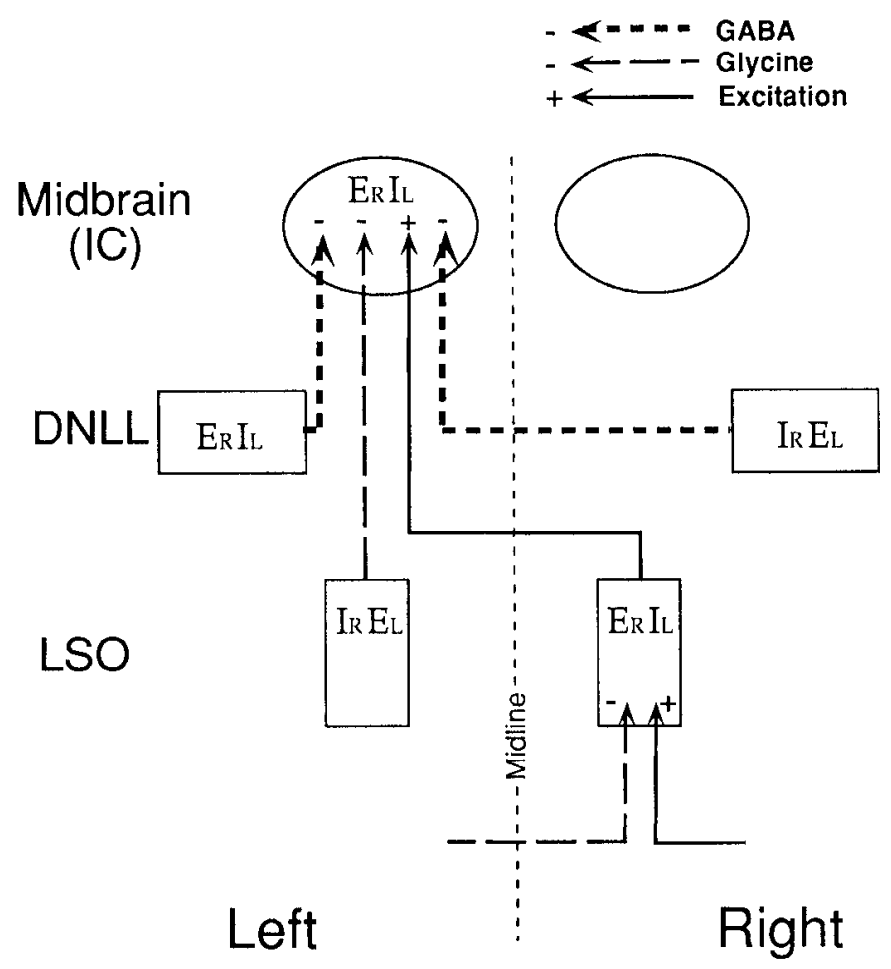

Figure 1. Schematic diagram of the excitatory/inhibitory (EI) projection system to the left inferior colliculus $(I C)$. The ears providing the excitatory $(+)$ and inhibitory $(-)$ inputs to each nucleus are indicated. The large letters in each nucleus indicate that neurons in that nucleus receive excitatory $(E)$ and inhibitory $(I)$ inputs, while the small letters signify whether it is the right or the left ear that provides the excitation or inhibition. Thus, ERIL in the right lateral superior olive $(L S O)$ signifies excitatory inputs from the right ear and inhibitory inputs from the left ear. Note that the right LSO, left dorsal nucleus of the lateral lemniscus $(D N L L)$, and left inferior colliculus all reccivc cxcitation from the right ear and inhibition from the left ear, and are ERIL. The left lateral superior olive and right dorsal nucleus of the lateral lemniscus have the inverse innervation and are IREL. Arrows indicate GABAergic glycinergic and excitatory projections. The projections from lateral superior olive to dorsal nucleus of lateral lemniscus, and the monaural excitatory projections from the right ear to the inferior colliculus are not shown.

properties are created in a lower nucleus and imposed upon the collicular cell via an excitatory projection, then the blockade of inhibitory inputs at the colliculus should have no effect on the cxpression of those response properties.

The experimental animals in this study were mustache bats. Like other bats, the mustache bat emits high-frequency calls and relies heavily on IIDs for localizing the echoes returning from objects in space (Fuzessery and Pollak, 1985; Wenstrup et al., 1986; Pollak and Casseday, 1989; Pollak, 1992). We recorded responses from a region of the hypertrophied $60 \mathrm{kHz}$ contour of the inferior colliculus dominated by excitatory/inhibitory neurons (Wenstrup et al., 1986; Ross and Pollak, 1989), whose response properties have been well documented in previous studies (Fuzessery and Pollak, 1985; Wenstrup et al., 1986, $1988 \mathrm{a}, \mathrm{b})$. In this report, we show that blocking GABAergic innervation has profound effects on the binaural properties of many excitatory/inhibitory collicular cells. We suggest that at least three GABAergic circuits shape excitatory/inhibitory features in the inferior colliculus, and discuss the implications of these findings for mechanisms of information processing relevant for sound localization. 


\section{Materials and Methods}

Surgical procedures. Fifteen Jamaican mustache bats, Pteronotus parnellii parnellii, were experimental subjects. Prior to surgery, animals were anesthetized with methoxyflurane inhalation (Metofane, PitmanMoore, Inc.) and $10 \mathrm{mg} / \mathrm{kg}$ of sodium pentobarbital injected intraperitoneally. The hair on the bat's head was removed with a depilatory and the head secured in a head holder with a bite bar. The muscles and skin overlying the skull were reflected, and lidocaine (Elkins-Sinn, Inc.) was applied topically to all open wounds. The surface of the skull was cleared of tissuc, and a ground electrode was placed just beneath the skull over the cerebellum. A layer of small glass beads and dental acrylic was placed on the surface of the skull to secure the ground clectrode and to serve as a foundation layer to be used later for fixing the head in the stereotaxic apparatus. A small hole (approximately $0.5-1.0 \mathrm{~mm}$ diameter) was then drilled over the left inferior colliculus using landmarks visible through the skull for orientation. We used only the left inferior colliculus of each animal.

The bat was transferred to a heated $\left(27-30^{\circ} \mathrm{C}\right)$, sound-attenuated room, where it was placed in a restraining apparatus attached to a custommade sterentaxic instrument (Schuller et al., 1986). A small metal rod was cemented to the foundation layer on the skull and then attached to a bar mounted on the stereotaxic instrument to ensure uniform positioning of the head. Recordings were begun after the bat was awake Intramuscular injections of the neuroleptic Innovar-Vet $(0.01 \mathrm{ml} / \mathrm{gm}$ body weight; Pitman-Moore, Inc.) were given if the bat appeared in discomfort.

Recording electrodes. Piggyback multibarrel microelectrodes were used for recordings and iontophoresis of drugs (Havey and Caspary, 1980). Single-barrel micropipettes were pulled to a tip diameter less than $1 \mu \mathrm{m}$ and filled with buffered $1 \mathrm{~m} \mathrm{NaCl}$ with $2 \%$ fast green $(\mathrm{pH} 7.4)$. Electrode impedances ranged from 5 to $20 \mathrm{M} \Omega$. Fast green was used to enhance the visibility of the electrode for placement in the small hole made in the skull. A five-barrel electrode (H-configuration; Omega dot, Glass Co. of America) was pulled and the tips were broken back under microscopic observation so that the tip diameter of the multibarrel array was $10-15 \mu \mathrm{m}$. The single-barrel micropipette that was used to record single units was then positioned at an angle of approximately $20^{\circ}$ to the five-barrel pipette, and glued with cyanoacrylate so that the tip of the single-barrel pipette protruded about $10 \mu \mathrm{m}$ in front of the broken tips of the five-barrel pipette. One of the multibarrcls was used to balance current. This balancing (sum channel) barrel was also filled with buffered $1 \mathrm{M} \mathrm{NaCl}$ and $2 \%$ fast green $(\mathrm{pH} 7.4)$. One cjection barrel was filled with GABA ( $500 \mathrm{~mm}$, pH 3.5-4.0; Sigma), and another with bicuculline methiodide ( $10 \mathrm{~mm}, \mathrm{pH} \mathrm{3.0;} \mathrm{Sigma).} \mathrm{The} \mathrm{other} \mathrm{barrels} \mathrm{were} \mathrm{filled} \mathrm{either}$ with the drug delivery vehicle $(0.16 \mathrm{M} \mathrm{NaCl}, \mathrm{pH} 3.5)$ or glycine $(100$ $\mathrm{mm}$, pH 3.5-4.0; Sigma) and strychnine (10 mm, pH 3.5-4.0; Sigma). All drugs were prepared just prior to each experiment, and the electrodes were filled immediately before use. Bicuculline was mixed with $0.16 \mathrm{M}$ $\mathrm{NaCl}$ in which the $\mathrm{pH}$ was adjusted to 3.0 by titration with $0.10 \mathrm{M} \mathrm{HCl}$. GABA was mixed in distilled water in which the $\mathrm{pH}$ was adjusted to 3.54 .0 with $0.10 \mathrm{M} \mathrm{HCl}$. The drug barrels and balancing barrel were connected via silver-silver chloride wires to a six-channel microiontophoresis constant-current generator (Medical Systems Neurophore BH2) that was used to generate and monitor iontophoretic currents. The sum channel was employed to balance current in the drug barrels and reduce current effects. The recording barrel of the microelectrode was connected by a silver-silver chloride wire to the head stage of a Dagan AC amplifier (model 2400). Electrode penetrations were made vertically through the cxposed dorsal surface of the inferior colliculus. Electrode placement was based on surface landmarks viewed with an operating microscope. Subsequently, the electrode was advanced from outside of the experimental chamber with a piezoelectric microdrive (Burleigh 712 IW).

Acoustic stimuli, data acquisition, and processing. A custom-made clectronic switch shaped sine waves from a Wavetek oscillator (Model 136) into $20 \mathrm{msec}$ tone bursts having $0.5 \mathrm{msec}$ rise-fall times. During data acquisition, the sound intensity of the bursts was selected pseudorandumly by a Macintosh IIci computer, which controlled an electronic attenuator (Wilsonics model PATT) via a 24-bit digital interface (Metrabyte MAC PIO-24) and a Digital Distributor (Restek model 99). The output of the attenuator went to two speakers (Panasonic ultrasonic ceramic loudspeaker EFR-OTB40K2). The speakers were fitted with plastic probe tubes $(5 \mathrm{~mm}$ diameter) that were placed in the funnels of each pinna. Maximum sound intensity was $85 \mathrm{~dB}$ SPL measured at 0.5 $\mathrm{cm}$ from the opening of the probe tubes. Sound pressure and the fre- quency response of the loudspeakers were measured with a $1 / 4$ inch Brüel and Kjaer microphone (type 4135) and a Brüel and Kjaer measuring amplifier (type 2608). Each speaker showed less than $\pm 3 \mathrm{~dB}$ variability for the frequency range used $(55-65 \mathrm{kHz})$, and intensities between the speakers did not vary more than $\pm 2 \mathrm{~dB}$ at any of those frequencies. Tone bursts were presented at a rate of four per second. Acoustic isolation between the ears was $40-50 \mathrm{~dB}$ and was determined empirically by testing monaural units during the course of the experiments. Monaural units were responsive to sound at the contralateral ear and were unaffected by ipsilateral sounds up to $40 \mathrm{~dB}$ higher in intensity than the threshold at the contralateral ear. After the threshold for the contralateral ear was determined, that speaker was turned off and the ipsilateral speaker was activated. The threshold difference, in decibels, between the ipsilateral and contralateral speakers was taken as a measure of acoustic isolation.

Only well-isolated spikes with a signal-to-noise ratio of at least 8 were studied. Spikes were fed to a window discriminator and the output of the discriminator was fed to the computer. When a unit was encountered, its characteristic frequency and absolute threshold were audiovisually determined in order to set stimulus parameters subsequently controlled by the computer. The characteristic frequency was defined as the frequency that elicited responses at the lowest sound intensity to which the unit was sensitive. Binaural stimuli were then presented to determine whether the unit was monaural or hinaural, and if it was binaural, whether it was excitatory/inhibitory or excitatory/excitatory. Units were classified as excitatory/inhibitory if sound at the inhibitory car suppressed the responses evoked by the contralateral ear by at least $50 \%$. For each excitatory/inhibitory unit, sounds at various intensities were presented monaurally to the ipsilateral ear, and the influence of this stimulation was monitored audiovisually. Only cells in which monaural stimulation of the ipsilateral ear did not evoke discharges were classified as excitatory/inhibitory.

Poststimulus time histograms were generated with characteristic-fre quency tone bursts presented 20 times in a pseudorandom order at each sound intensity or interaural intensity disparity. Histograms were displayed on the computer screen for inspection during the experiments and stored on hard disk for later analysis. A rate-intensity function was constructed for each unit from the responses generated with characteristic-frequency tone bursts presented to the excitatory ear at intensities from $10 \mathrm{~dB}$ below to $40 \mathrm{~dB}$ above threshold. An interaural intensity disparity (IID) function was generated next with sound intensity at the contralateral ear fixed at $10-20 \mathrm{~dB}$ above threshold and the intensity at the ipsilateral ear varied from about $20 \mathrm{~dB}$ below to $30 \mathrm{~dB}$ above the intensity at the excitatory ear. All units were checked to ensure that at least one IID used a low-cnough intensity at the inhibitory ear so that the evoked discharge rate was comparable to the rate evoked by the excitatory ear alone.

Responses were recorded before during and after drug application. When a drug was not being applied, a retention current of $15 \mathrm{nA}$ (electrode negative) was applied to each drug barrel to prevent leakage of drugs. Drugs were iontophoretically applied by turning off the negative retention current and switching to a positive ejection current. The iontophoretic application of GABA produced a rapid dose-dependent inhibition in all collicular cells. Complete inhibition of discharges was achicved with ejection currents of $\mathrm{G} A \mathrm{~B} A$ ranging from $5 \mathrm{nA}$ to $50 \mathrm{nA}$. Bicuculline took a much longer time than GABA to exert its effects. A change in firing ratc typically occurred within the first minute following application of bicuculline, but the firing rate usually took $2-5$ inin to stabilize. The effect of bicuculline was to increase the firing rates in all but a few collicular neurons. The increases in discharge rate, moreover, always occurred in a dose-dependent fashion. The increases in firing rate caused by bicuculline could be inhibited by the simultaneous application of GABA.

The effects on monaural rate-intensity functions were initially evaluated with a low ( $5 \mathrm{nA}$ electrode positive) ejection current of bicuculline. Rate-intensity functions were obtained until the shape and maximum spike count stabilized, and then the current was increased and the procedure repeated. The currents most frequently employed ranged from 5 to $20 \mathrm{nA}$. Higher currents were sometimes employed with neurons whose firing rates increased with ejection currents of $20 \mathrm{nA}$. Electrode resistance was monitored continuously, and only cases in which resistance did not change throughout drug application are reported. The applied voltage that maintained the constant ejection currents was also monitored and was within the range reported by Purves (1981) for a linear relation between drug release and ejection current.

To assure that changes in rate-intensity functions were due to bicu- 


\section{A Right (Excitatory) Ear Only}
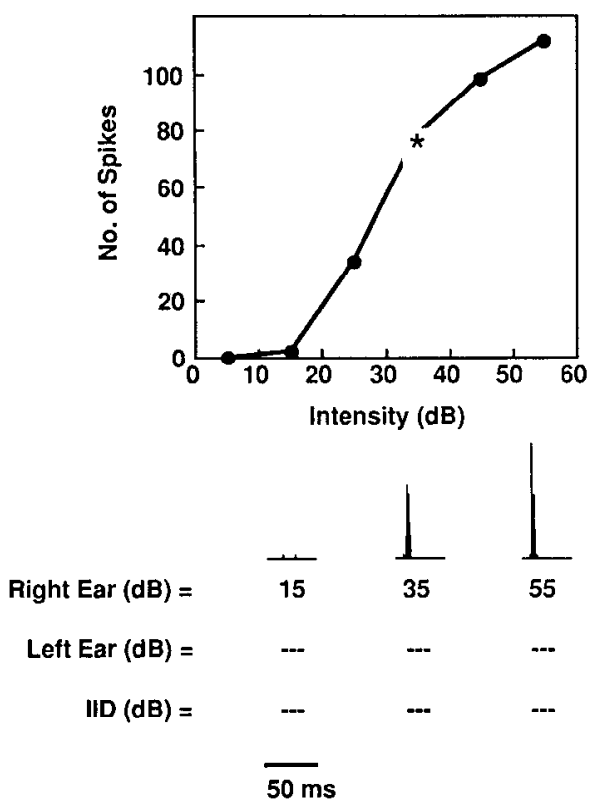

culline and not to the applied current, responses were obtained when drugs were not ejected but a current equal to the bicuculline ejection current was passed through the balancing barrel. Those responses were compared to the predrug and bicuculline-induced responses. To control for any effects that the low $\mathrm{pH}$ of the vehicle might cause, current was passed through the vehicle alone. The responses of two cells appeared to be influenced by current artifacts, so the data for those cells were discarded and the electrodes were immediately replaced. An account of the general effects of GABA, bicuculline, and vehicle alone on cells in the mustache bat's inferior colliculus has been presented elsewhere (Pollak and Park, 1993).

Five units displayed a substantial degree of spontaneous activity. The amount of spontaneous activity was measured for each of these cells by recording the number of responses when the speakers were inactivated for predrug, drug, and recovery conditions. The number of spontaneous responses was then subtracted from the number of acoustically evoked responses at each intensity tested.

After collecting data with bicuculline, the ejection current was switched off and the cell was allowed to recover. Recovery was complete when the shape of the rate-intensity function and the maximum spike count returned to predrug form. Recovery from bicuculline occurred over periods ranging from a few minutes up to $30 \mathrm{~min}$ depending on the previous ejection current and the length of time bicuculline had been applied. We assessed recovery with monaural response properties because the units were part of a larger project in which we evaluated the effects of bicuculline and strychnine on a variety of monaural as well as binaural response features. A report on the effects of bicuculline on monaural response properties has appeared previously (Pollak and Park, 1993), while the effects of strychnine will be the subjects of future reports. However, in 15 units we obtained recovered IID functions in addition to the rate-intensity function. When the rate-intensity function recovered in each unit, the IID functions, all of which changed substantially with bicuculline, also recovered and exhibited their predrug forms.

\section{Results}

We studied 83 binaural neurons from the central nucleus of the inferior colliculus. Recordings were from the hypertrophied 60 $\mathrm{kHz}$ isofrequency contour in the left inferior colliculus, and all cells were excited by the contralateral ear and inhibited by the ipsilateral ear. Because the excitatory/inhibitory projection system involves both contralateral and ipsilateral structures as well as crossed and uncrossed projections, we will refer to structures
Figure 2. Response characteristics of an EI neuron. $A$, Kate-intensity function generated by monaural tone bursts at the right (excitatory) ear. The threshold was about $15 \mathrm{~dB}$. At $35 \mathrm{~dB}(20 \mathrm{~dB}$ above threshold), the unit responded with 78 spikes (asterisk), and responding increased at higher intensities. $B$, IID function generated by setting the intensity at the right ear at $35 \mathrm{~dB}$ and presenting sound to the left (inhibitory) ear at a variety of intensities. With the lowest intensity at the left ear (asterisk), 77 spikes were evoked, which is comparable to the response evoked by stimulating the right ear alone at $35 \mathrm{~dB}$. Increasing the intensity at the left ear, which produced more negative IIDs, caused the discharge rate to decline, and with the highest intensity at the left ear ( -20 dB IID), responses were completely suppressed. At the bottom of the IID function, left $(L)$ and right $(R)$ indicate the ear at which the sound was more intense. The histograms below the graphs show the discharge patterns evoked by monaural stimulation $(A)$ and binaural stimulation $(B)$ at the intensities and IIDs indicated. as being on the left or right. Hence, excitatory/inhibitory cells in the left colliculus were excited by sound at the right (contralateral) ear and inhibited by sound at the left (ipsilateral) ear. The response properties of each neuron were evaluated with a range of IIDs. The disparities were generated by holding sound intensity at the right (excitatory) car constant at 10-20 dB above threshold and varying the intensity at the left ear. By convention, IIDs are assigned a positive value if the intensity at the right (excitatory) ear was greater than the intensity at the left (inhibitory) ear, and a negative value if the intensity at the right ear was less than the intensity at the left ear. We point out that in several previous reports (Fuzessery and Pollak, 1985; Wenstrup et al., 1986, 1988a,b; Fuzessery et al., 1990), positive IIDs indicated that sound at the inhibitory ear was stronger than at the excitatory ear. However, the convention used by almost all other investigators is that a positive IID indicates stronger sound at the excitatory ear, and we therefore conform here with the generally accepted use of positive and negative IIDs.

\section{Features of binaural response properties prior to drug application}

There were two types of IID functions. Fifty-eight (70\%) of the cells had conventional IID functions where the firing rate evoked by a fixed intensity at the right (excitatory) ear remained constant with low intensities at the left (inhibitory) ear, and then declined progressively as the intensity at the left ear increased (Fig. 2). We refer to cells that had this type of IID function as EI neurons. The IID functions of the remaining 25 cells (30\%) showed binaural facilitation and were classified as $E I / f$ neurons [Fig. 3; in previous studied these cells also have been called EO/ IF (Fuzessery and Pollak, 1985; Fuzessery et al., 1990), peaked (Semple and Kitzes, 1987), and nonmonotonic (Irvine and Gago, 1990)]. In these cells, increasing sound intensity at the left (inhibitory) ear initially caused the firing rate to increase by at least $25 \%$ above the rate evoked by the sound at the right (excitatory) ear alone. Additional intensity increases at the left (inhibitory) ear then resulted in a marked decline in response rate. 
Figure 3. Response characteristics of an $\mathrm{EI} / \mathrm{f}$ neuron. $A$, Rate-intensity function showing that the unit responded with 16 spikes at $25 \mathrm{~dB}$ (asterisk). $B$, IID function generated by fixing intensity at the right (excitatory) ear at 25 $\mathrm{dB}$. At the lowest intensity presented to the left (inhibitory) ear, the unit responded with 15 spikes (asterisk), which was comparable to the spike count evoked by stimulating the right ear alone at $25 \mathrm{~dB}$. As the intensity at the left ear increased, which produced more negative IIDs, the discharge rate more than doubled to 37 spikes at $0 \mathrm{~dB}$ IID, and then declined rapidly as intensity at the left ear was increased further. At the highest inhibitory intensity, when the IID was $-20 \mathrm{~dB}$, the unit was almost completely suppressed. At the bottom of the IID function, left $(L)$ and right $(R)$ indicate the ear at which the sound was more intense. The histograms below the graphs show the discharge patterns evoked by monaural stimulation $(A)$ and binaural stimulation $(B)$ at the intensities and IIDs indicated.
Right (Excitatory) Ear Only

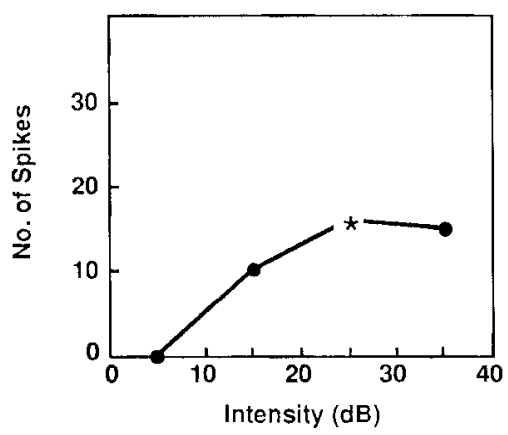

\begin{tabular}{|c|c|c|c|c|}
\hline & & عسل ميل & $L$ & $\perp$ \\
\hline Right Ear $(\mathrm{dB})=$ & 5 & 15 & 25 & 35 \\
\hline Left Ear $(\mathrm{dB})=$ & -- & -- & --- & -.. \\
\hline$\| D(d B)=$ & -- & n-m & $\cdots$ & -... \\
\hline
\end{tabular}

Both Ears
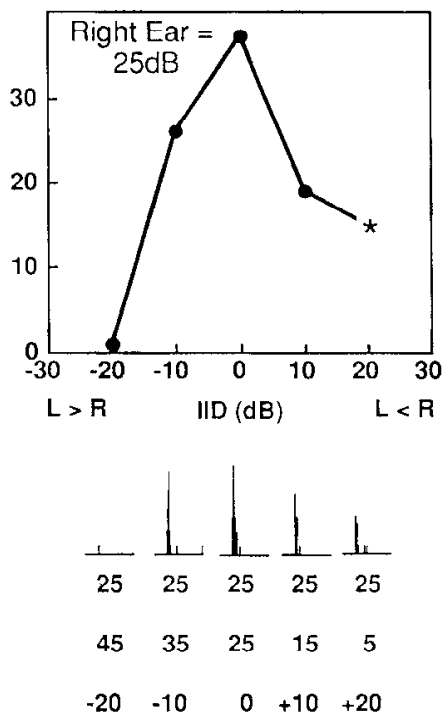

Quantitative measures of two binaural properties were derived from the IID functions of both $\mathrm{EI}$ and $\mathrm{EI} / \mathrm{f}$ neurons. The first measure was the maximum inhibition, the percentage by which the response evoked by the right (excitatory) ear was reduced due to stimulation of the left (inhibitory) ear (Wenstrup et al., 1988a). For EI/f units, the peak response to binaural stimulation was compared to the minimum response evoked by the highest intensity at the left (inhibitory) ear. The second was the $50 \%$ point, the IID at which the response evoked by the right (excitatory) ear declined by $50 \%$ (50\% points were previously called inhibitory thresholds by Wenstrup et al., 1988a,b).

Quantitative values of both features varied among the units sampled. The values of maximum inhibition ranged from $50 \%$ to $100 \%$ (Fig. $4 A$ ). Three units illustrating the range of maximum inhibitions are shown in Figure 5. The unit in Figure $5 \mathrm{~A}$ was weakly inhibited by the left (inhibitory) ear and had a maximum inhibition of about $60 \%$. The maximum inhibition of the unit in Figure $5 B$ was $80 \%$, and the unit in Figure $5 \mathrm{C}$ had a maximum inhibition of $100 \%$. The majority of units $(65 \%)$ were strongly inhibited and had maximum inhibitions of at least $80 \%$. The distribution of maximum inhibitions among our sample is in close agreement with the distribution reported previously (Wenstrup et al., 1988a).

The $50 \%$ point IIDs ranged from $+15 \mathrm{~dB}$ right ear stronger to $-30 \mathrm{~dB}$ left ear stronger (Fig. $4 B$ ). In 65 cells $(78 \%$ ) the $50 \%$ points occurred at IIDs that were zero or negative, where the response rate was reduced by $50 \%$ when the intensity at the left (inhibitory) ear was equal to or greater than the intensity at the right (excitatory) ear. Figure $6, B$ and $C$, shows two units in which the IIDs of the $50 \%$ points were $0 \mathrm{~dB}$ and $-20 \mathrm{~dB}$ left ear stronger, respectively. The $50 \%$ points of 18 of the units $(22 \%)$ were at positive IIDs; the response rate was reduced by $50 \%$ when sound at the (right) excitatory ear was stronger than the (left) inhibitory ear. An example is the unit in Figure $6 \mathrm{~A}$. The distribution of $50 \%$ points shown in Figure $4 B$ is similar to that found previously (Wenstrup et al., 1988a).

\section{Effects of bicuculline on maximum inhibition}

The effects of hicuculline on maximum inhibition spanned the continuum from no change in maximum inhibition to complete elimination of inhibition evoked by the left (inhibitory) ear. We arbitrarily divided the $83 \mathrm{EI}$ and EI/f units into three categories based on the degree to which bicuculline reduced maximum inhibition. Units in the first category had maximum inhibitions that were either minimally affected or not affected at all by bicuculline. In these units, the difference between the predrug maximum inhibition and the maximum inhibition with bicuculline was less than $25 \%$ (Fig. $7 \mathrm{~A}$ ). Units in the second category had a moderate bicuculline-induced reduction in maximum inhibition. For these units, bicuculline caused the maximum inhibition to decline by $25-50 \%$ (Fig. $7 \mathrm{~B}$ ). Units in the third category were profoundly affected by bicuculline and exhibited reductions of morc than $50 \%$ in maximum inhibition (Fig. $7 \mathrm{C}$ ). Of the 83 units, the maximum inhibitions of 52 neurons were largely unaffected by bicuculline, 17 units displayed moderate reductions, and the maximum inhibitions of 14 units were strongly affected by bicuculline. Thus, 31 cells $(37 \%$ when the moderately and strongly affected categories were combined) showed a substantial reduction or elimination of maximum inhibition with bicuculline.

Before continuing, we point out some factors inherent with the microiontophoresis of bicuculline other than its antagonism for GABA receptors, and show that those factors probably did not contribute to the above results. We turn first to the cells in which bicuculline caused a large reduction or in some cases a complete elimination of ipsilaterally evoked inhibition and show why those results were almost certainly due to a blockage of the GABAergic innervation from the left (inhibitory) ear and not to a saturation of response rate. One feature associated with bicuculline is that it causes an overall increase in response magnitude in almost all collicular neurons (Faingold et al., 1989, 1991; Pollak and Park, 1993). A saturation effect could occur 


\section{A Distribution of Maximum Inhibitions}

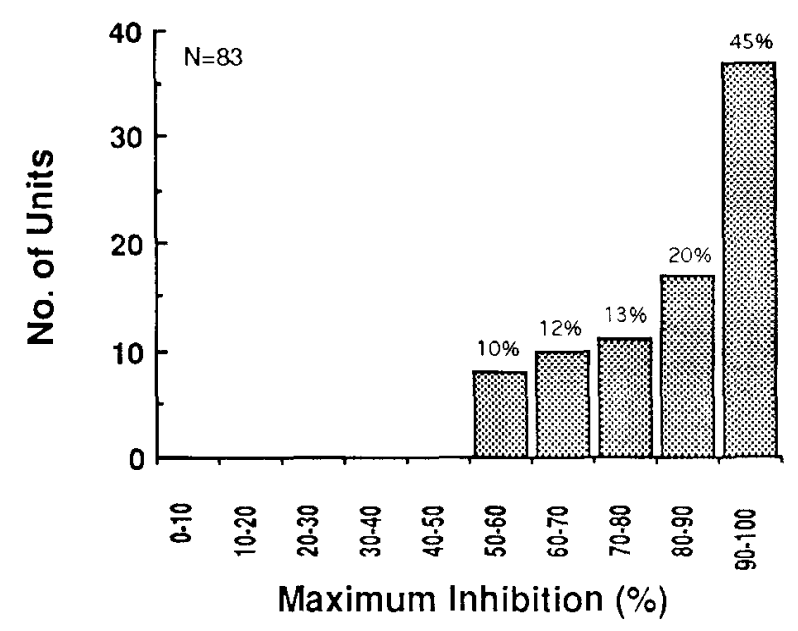

B

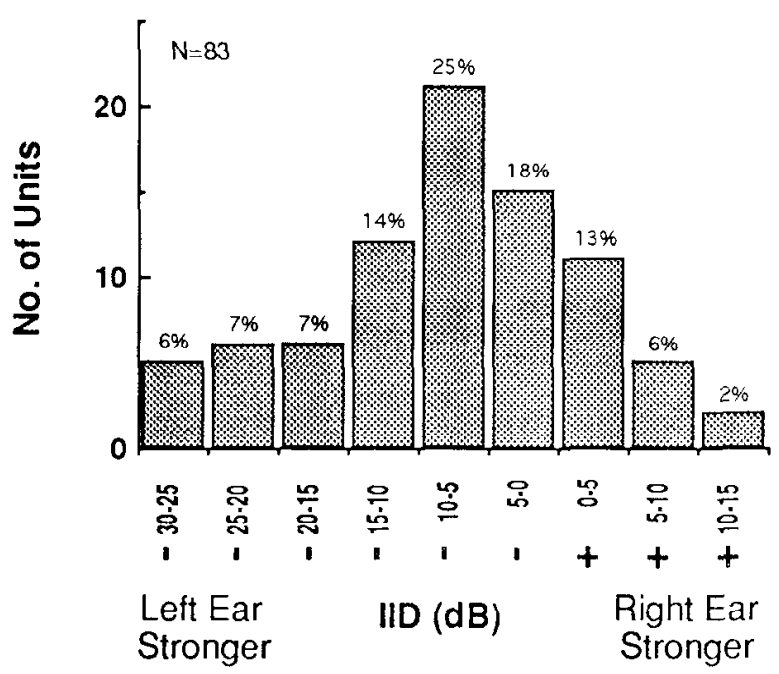

Figure 4. Distribution of maximum inhibition $(A)$ and $50 \%$ point IID $(B)$ values for $83 \mathrm{EI}$ and $\mathrm{EI} / \mathrm{f}$ units.

if the increase in discharge rate was so great that the rate could not be reduced by the inhibition evoked by the left (inhibitory) ear. In other words, the inhibition evoked by the left (inhibitory) ear might have been present in these cells, although it appeared that the inhibition was eliminated because its expression was overwhelmed by a large overall increase in response magnitude caused by bicuculline. Saturation effects, however, could not account for the elimination of maximum inhibition in the unit shown in Figure $7 C$. While the discharge rate evoked by a $5 \mathrm{~dB}$ signal at the right (excitatory) ear was elevated from 30 spikes in the predrug condition to 55 spikes by bicuculline, a rate of 55 spikes was within the unit's dynamic response range as shown by the arrow on the rate-intensity function in Figure $7 C$ (inset). It follows that if the inhibition evoked by the left (inhibitory) ear were present, it should have greatly reduced or eliminated completely the responses evoked by the $5 \mathrm{~dB}$ sound at the right
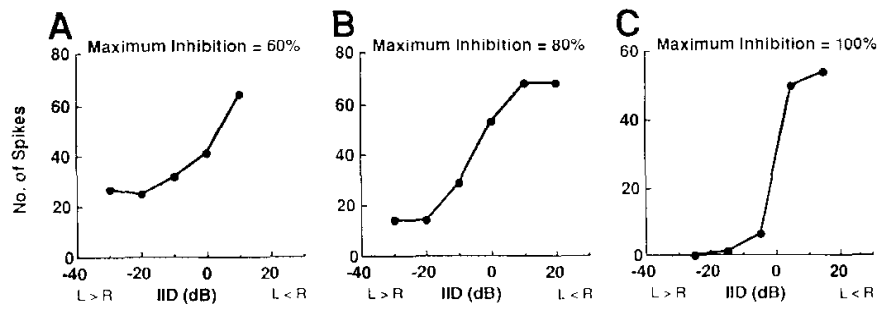

Figure 5. Three units with different maximum inhibitions. $A$, Unit with a maximum inhibition of $60 \%$. This unit responded with 68 spikes to a tone burst presented to the right (excitatory) ear alone at $10 \mathrm{~dB}$ above threshold (not shown), and had a similar rate of 64 spikes when the sound intensity at the left ear was low (IID of $+10 \mathrm{~dB}$ ) in the binaural condition. When the intensity at the left (inhibitory) ear increased by $40 \mathrm{~dB}$ (IID of $-30 \mathrm{~dB}$ ), the firing rate decreased to 27 spikes, and thus the rate declined by about $60 \% . B$ and $C$ Units with maximum inhibitions of $80 \%$ and $100 \%$, respectively. Left $(L)$ and right $(R)$ below the graphs indicate the ear at which the sound was more intense.

(excitatory) ear. Since the discharge rate under the binaural conditions tested was the same as that evoked by the right (excitatory) car alone, it is reasonable to conclude that the inhibitory inputs evoked by the left ear were blocked by bicuculline, thereby rendering the cell monaural.

With regard to the 52 cells in which bicuculline had little or no effect on maximum inhibition, the possibility exists that the drug failed to block GABAergic receptors in those neurons. This explanation is unlikely because bicuculline not only increased response magnitudes, but in most units affected other response properties as well. The effectiveness of bicuculline on monaural response properties in a unit whose maximum inhibition was unaffected by the drug is illustrated in Figure 8 . The predrug rate-intensity and IID functions are shown in the top panels of Figure 8 , and the same functions obtained with two dosages of bicuculline are shown in the lower panels. The significant feature is that while the maximum inhibition remained at or near $100 \%$ and thus was unaffected by bicuculline, the discharge rate evoked by $20 \mathrm{msec}$ tone bursts at the right (excitatory) ear increased from a predrug maximum of 17 spikes to 373 spikes at the highest dosage of bicuculline. In addition, the rate-intensity function was transformed from a predrug nonmonotonic function to one that was monotonic at the highest dosage of bicuculline. However, the possibility remains that bicuculline may not have reached the $\mathrm{GABAergic}$ receptors innervated by inputs from the left (inhibitory) ear, although it blocked the GABAergic inputs from the right (excitatory) ear that affected discharge rates and rate-intensity functions. As we show below, this was also unlikcly because in many cells whosc maximum inhibitions were unaffected by bicuculline, the antagonist changed cither the cell's $50 \%$ point IID, its binaural facilitation, or both.
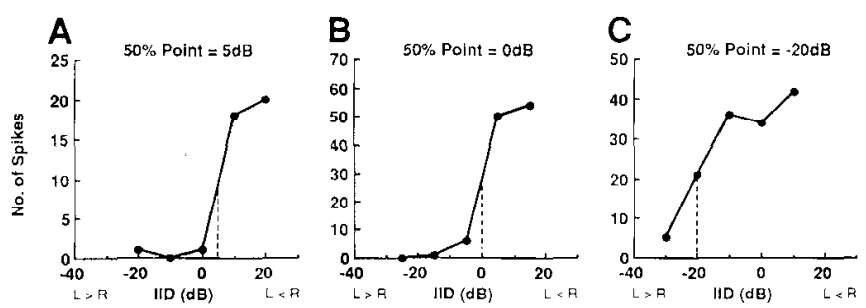

Figure 6. Three units with different $50 \%$ point IIDs. The broken lines indicate where the discharge rate declined by $50 \%$. Note different scales for number of spikes in each panel. 

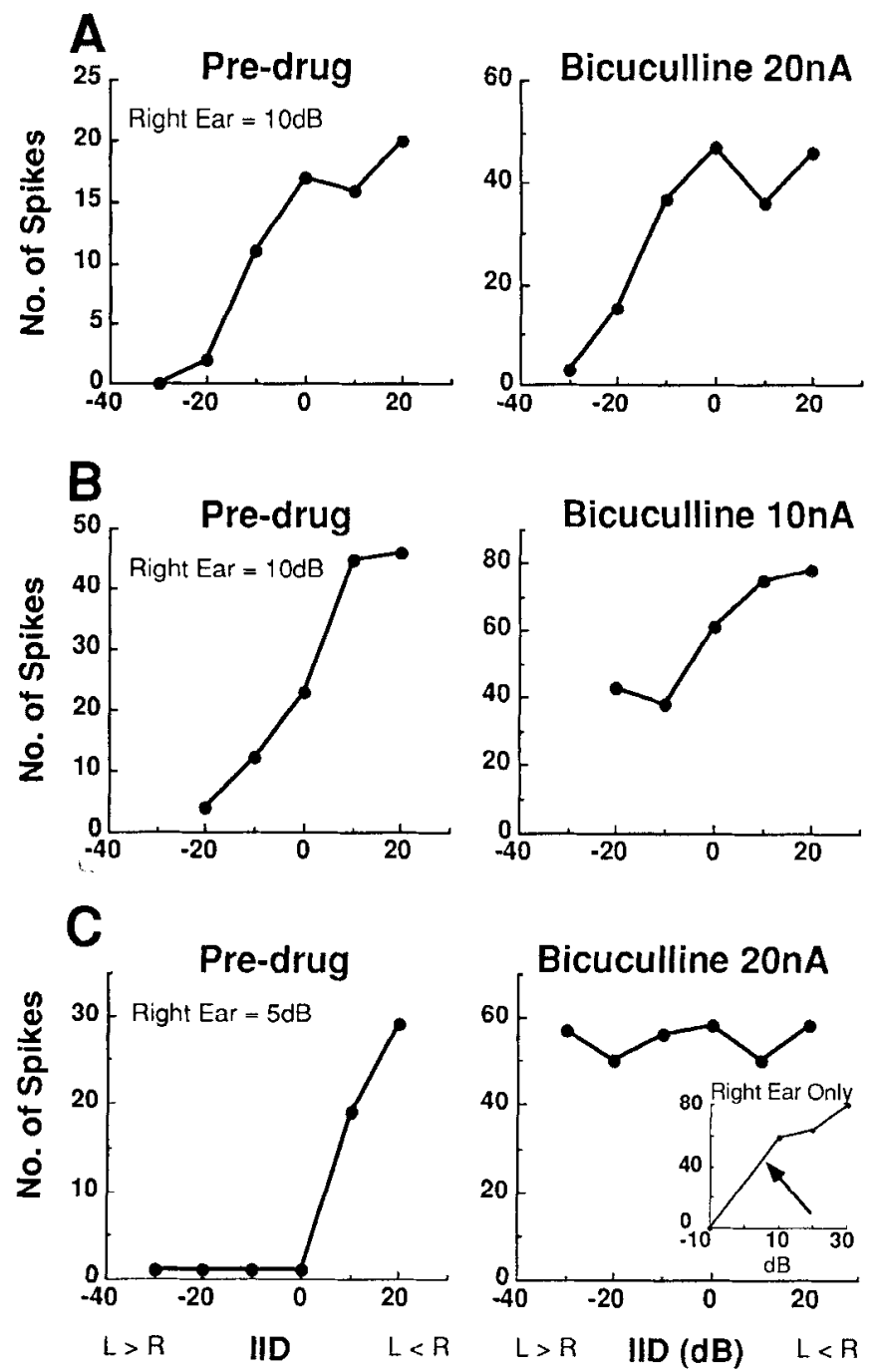

Figure 7. Effects of bicuculline on the maximum inhibitions of three neurons. Sound intensity at right ear is shown in each predrug IID function, and was $10 \mathrm{~dB}$ above threshold for each unit. $A$, IID functions before and during application of bicuculline for an EI unit whose maximum inhibition changed minimally with bicuculline. Bicuculline had little effect on the shape of the IID function or on maximum inhibition, even though it doubled the overall spike count. Threshold at the right (excitatory) ear was $0 \mathrm{~dB}$. $B$, Neuron showing a moderate change in maximum inhibition with bicuculline. In the predrug binaural condition, responses were almost completely suppressed by negative IIDs (left ear stronger). With bicuculline, high intensities at the left ear still inhibited discharges, although the decline in response rate was far less than in the predrug condition. Threshold at the right ear was $0 \mathrm{~dB}$. $C$, Neuron showing a large change in maximum inhibition with bicuculline Prior to bicuculline, responses were strongly inhibited at IIDs of $0 \mathrm{~dB}$ and with more negative IIDs (left ear stronger). With bicuculline, inhibition from the left (inhibitory) ear was blocked and the cell became monaural. The inset shows the rate-intensity function with $20 \mathrm{nA}$ of bicuculline. The arrow shows the discharge rate evoked by monaural stimulation of the right (excitatory) ear at $5 \mathrm{~dB}$, which was the intensity at the right ear in the binaural condition. Threshold at right ear was -5 $\mathrm{dB}$. Left $(L)$ and right $(R)$ at bottom of the graphs indicate the ear at which the sound was more intense. Note that the $y$-axis (number of spikes) was scaled so that the maximum value in each graph was close to the maximum spike count.

\section{Effects of bicuculline on 50\% points}

Thirty cells (59\%) in which bicuculline had little or no effect on maximum inhibition displayed bicuculline-induced changes in the IID of their $50 \%$ points of at least $+5 \mathrm{~dB}$ (Fig. 9). In 26
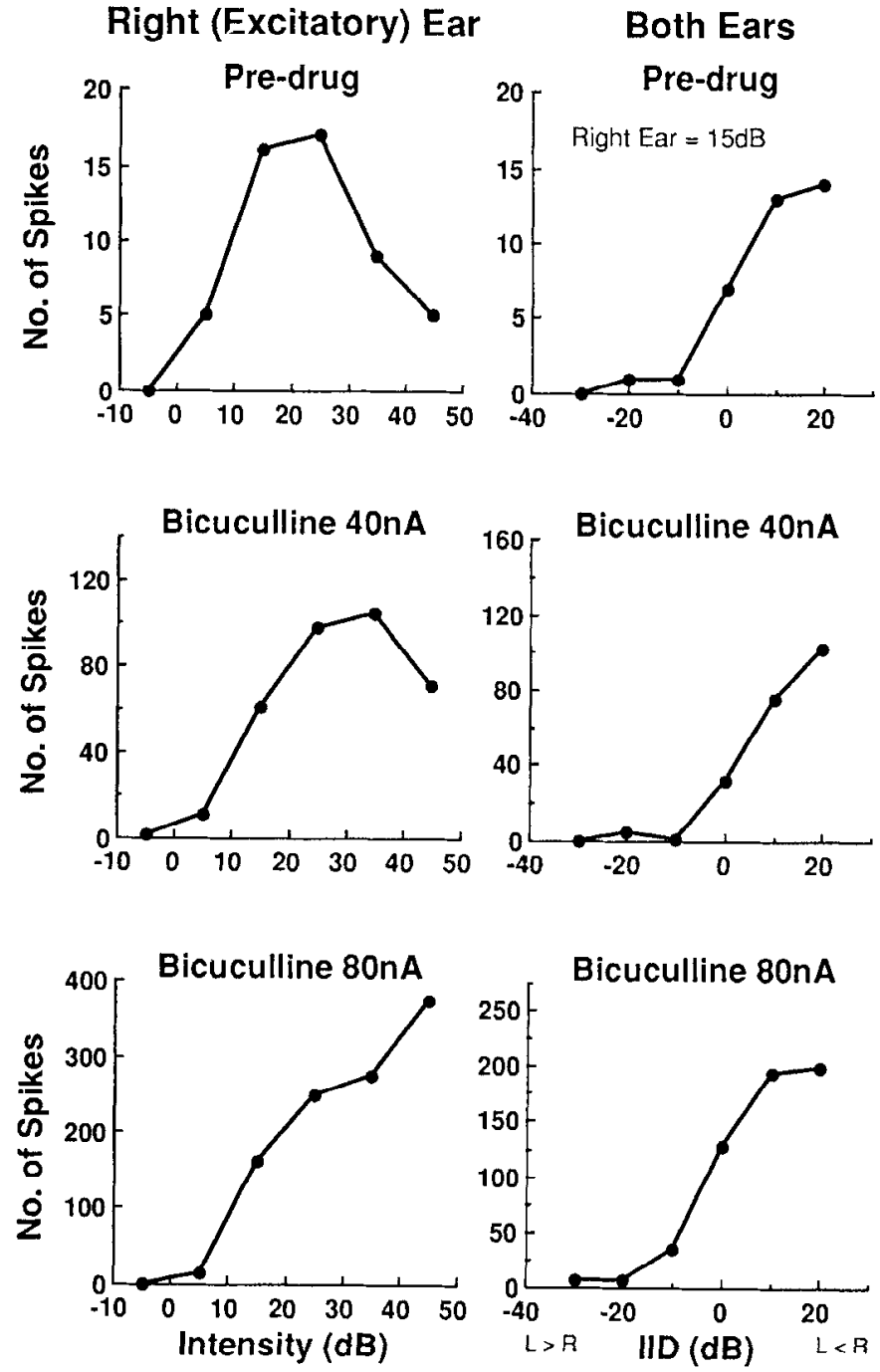

Figure 8. Example of a unit that showed a minimal change in its maximum inhibition and $50 \%$ point IID, but large dose-dependent changes in monaural response properties. The panels on the left show the rate-intensity functions for the right (excitatory) ear prior to bicuculline and with two dosages of bicuculline, $40 \mathrm{nA}$ and $80 \mathrm{nA}$. Each dosage increased the overall discharge rate and progressively changed the shape of the rate-intensity function from a strongly nonmonotonic function to one that was monotonic. The panels on the right show IID functions for the predrug and bicuculline conditions. Note different scale for number of spikes in each panel.

cells, the $50 \%$ points shifted to more negative IIDs with bicuculline, such that a more intense signal at the left (inhibitory) ear was required to produce the criterion inhibition than in the predrug condition. An example of a unit whose $50 \%$ point changed by $-14 \mathrm{~dB}$ such that the sound at the left (inhibitory) ear had to be $14 \mathrm{~dB}$ more intense than in the predrug condition is shown in Figure 10. In four other units, 50\% points changed in the other direction to more positive IIDs such that the intensity at the left (inhibitory) ear that produced $50 \%$ suppression was lower with bicuculline compared to the predrug condition.

\section{Effects of bicuculline on binaural facilitation}

Bicuculline affected binaural facilitation in 20 of the $25 \mathrm{EI} / \mathrm{f}$ cells. In six cells, bicuculline reduced the amount of facilitation but did not completely abolish it (e.g., Fig. 14). However, in 14 cells bicuculline eliminated binaural facilitation. Elimination of 


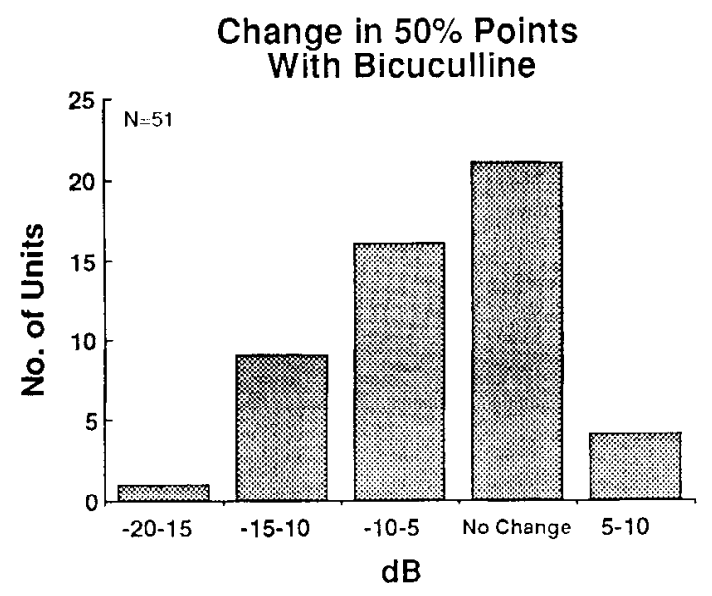

Figure 9. Histogram showing the bicuculline-induced changes in 50\% point IIDs. The histogram shows 51 units in which bicuculline caused little or no change in maximum inhibition. In 21 units, bicuculline had no effect on the IID at the $50 \%$ point, while in 30 units bicuculline caused the IID at the $50 \%$ point to shift by at least $+5 \mathrm{~dB}$. Negative values indicate that a greater intensity was required at the left (inhibitory) ear to suppress discharges with bicuculline than in the predrug condition.

facilitation was observed in $\mathrm{EI} / \mathrm{f}$ units independent of changes in maximum inhibition. Thus, binaural facilitation was reduced or lost in some cells that also had profound or moderate reductions in maximum inhibition with bicuculline, whereas in other cells maximum inhibition was affected minimally or not at all.

We illustrate this selective effect of bicuculline with the unit in Figure 11. The first feature to note in the predrug functions is that the response rate evoked by sound at the right (excitatory) ear alone was sinilar to the response rate evoked with binaural stimulation when the intensity at the left (inhibitory) ear was very low (asterisk in Fig. 11A,B). As the intensity at the left (inhibitory) ear changed from a low to a moderate intensity (IID of $0 \mathrm{~dB}$ ), the response rate more than doubled and thus was facilitated. With additional intensity increases at the left (inhibitory) ear, the discharges declined progressively and were almost completely suppressed by the highest intensity presented at the left ear. The application of bicuculline caused changes in both monaural and binaural response properties. One change was an overall increase in response magnitude, which can be seen in the rate-intensity function in Figure $11 \mathrm{C}$. With binaural stimulation, a very low sound intensity at the left (inhibitory) ear evoked a discharge rate that was similar to the rate evoked by the contralateral ear alone (Fig. $11 D$ ), as was the case in the predrug condition. However, bicuculline eliminated the binaural facilitation since there was no longer a systematic increase in discharge rate as the sound at the left (inhibitory) ear increased from low to moderate intensities. In addition, bicuculline had a small effect on the maximum inhibition; with the highest intensity at the left (inhibitory) ear, the response was clearly inhibited but not as strongly as it had been in the predrug condition. In short, bicuculline transformed the facilitated IID function into that of a conventional EI cell.

\section{Effects of bicuculline dosage on binaural inhibition}

The effects of bicuculline reported above represent a conservative estimate of the role that GABAergic innervation plays in shaping binaural inhibition. One reason is that in most units
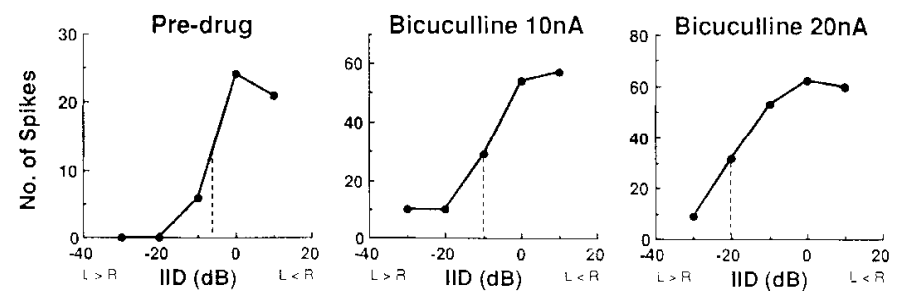

Figure 10. Example of a unit that showed relatively little change in its maximum inhibition with bicuculline but had dose-dependent shifts of its $50 \%$ point IID. The broken line shows the IID at which the discharge rate declined by $50 \%$. The predrug $50 \%$ point IID was $-6 \mathrm{~dB}$ (left). The $50 \%$ point IID shifted to $-10 \mathrm{~dB}$ with $10 \mathrm{nA}$ of bicuculline (center), and shifted to $-20 \mathrm{~dB}$ with $20 \mathrm{nA}$ of bicuculline (right). Note the different scale for number of spikes in each panel. Left $(L)$ and right $(R)$ at bottom of graphs indicate the ear at which the sound was more intense.

we utilized only one iontophoretic current (dosage) for the ejection of bicuculline. The currents used were usually below 50 $\mathrm{nA}$, and we are uncertain as to whether higher doses of bicuculline would have produced more profound effects. For example, bicuculline caused a moderate reduction in maximum inhibition with a particular ejection current in units such as the one shown in Figure $7 \mathrm{~B}$. What is unclear is whether a greater decrease in maximum inhibition could have been achieved had a higher ejection current also been used.

In 15 units, however, we evaluated the effects of more than one dosage of bicuculline on binaural inhibition. In five of these
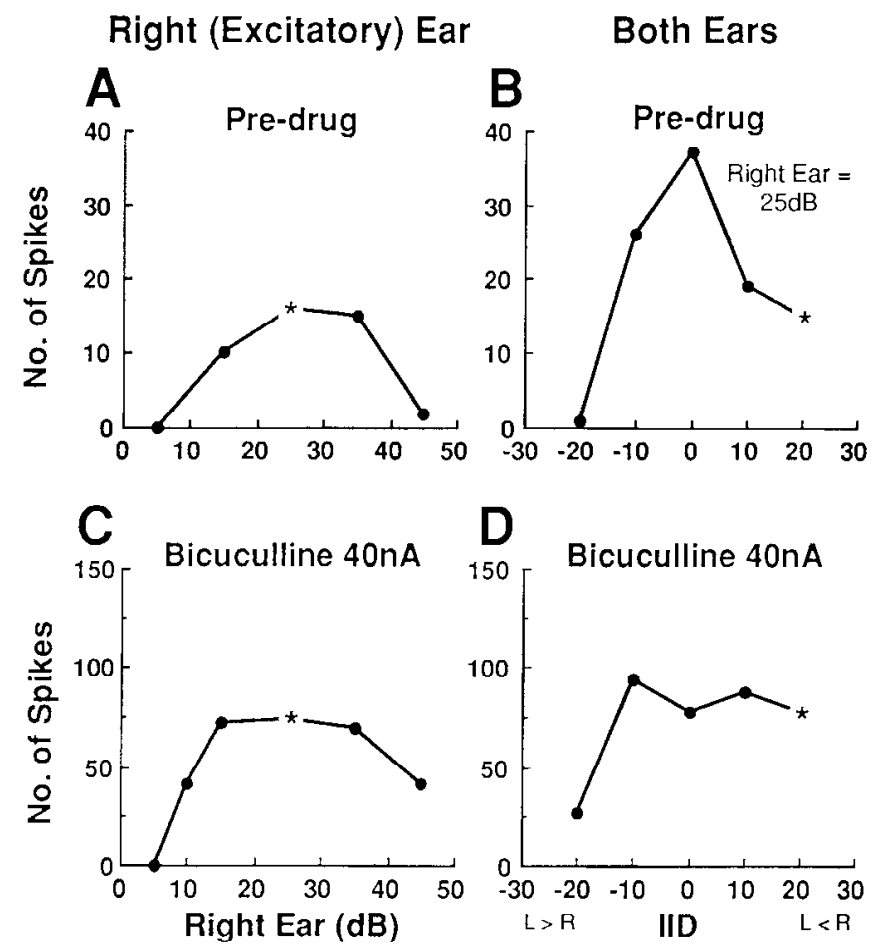

Figure 11. EI/f unit in which bicuculline eliminated binaural facilitation but had only a minor effect on maximum inhibition. $A$ and $B$, Predrug rate-intensity and IID functions, respectively. $C$ and $D$, Rateintensity and IID functions during bicuculline application. The function in $B$ shows facilitation at IIDs of 0 and $-10 \mathrm{~dB}$. $D$ shows that bicuculline eliminated facilitation but that the maximum inhibition declined only slightly. Note the different scale for number of spikes in predrug and bicuculline panels. Left $(L)$ and right $(R)$ at bottom of graphs indicate the ear at which the sound was more intense. 

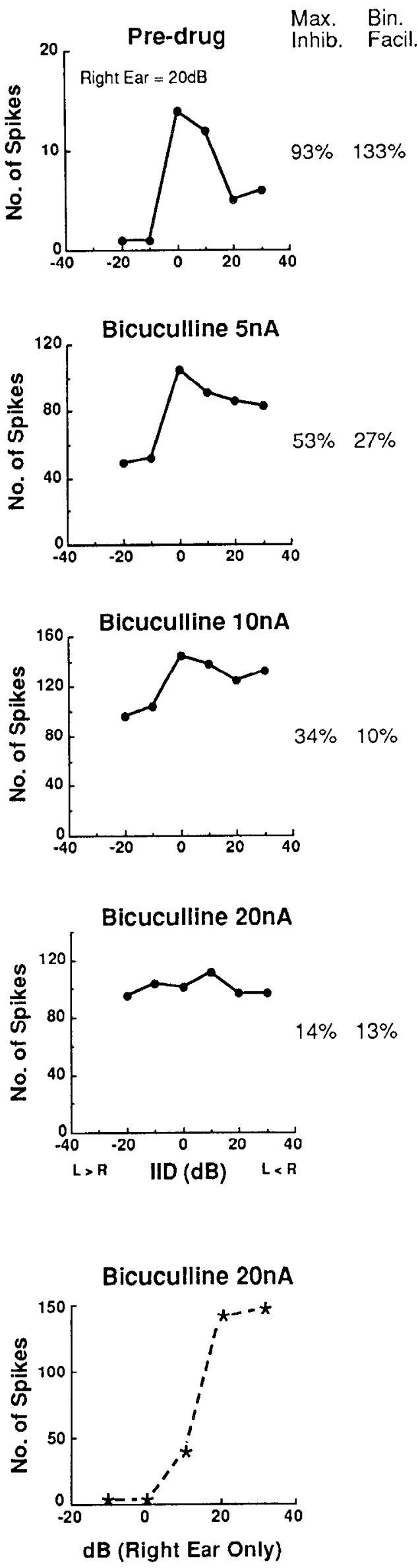

units, the effects on maximum inhibition and $50 \%$ points did not change with dosage even though the rate-intensity functions changed markedly. An example is the unit in Figure 8. In 10 units, however, there were clear dose-dependent effects on one or more measures of binaural inhibition. The unit in Figure 10, for example, showed dose-dependent changes in the $50 \%$ point IID with only a minimal change in maximum inhibition. In other units there were substantial dose-dependent effects on maximum inhibition and/or binaural facilitation, as illustrated by the EI/f unit in Figure 12. In this unit, the maximum inhibition declined progressively as bicuculline dosage was increased, and was essentially eliminated by the highest dosage of bicuculline (the cell became monaural). Increasing doses of bicuculline also initially reduced and then eliminated the binaural facilitation. It should be noted that although the lowest dosage of bicuculline $(5 \mathrm{nA})$ caused a substantial increase in the overall response magnitude, the progressive changes in binaural inhibition at $10 \mathrm{nA}$ and $20 \mathrm{nA}$ occurred without a significant additional increase in firing rate. It is also noteworthy that the response rate evoked by binaural stimulation with $20 \mathrm{nA}$ of bicuculline was substantially below the maximum rate of the monaural rate-intensity function. These features show that both the elimination of the facilitation and the elimination of the inhibition were not by-products of a saturated response rate that could neither be increased by an additional excitation nor decreased by a moderate inhibitory drive.

A dose-dependent reduction in binaural facilitation and maximum inhibition is also illustrated by the weakly inhibited EI/ $f$ unit in Figure 13. This neuron is of interest because the effect of bicuculline on the discharge rate was different at an IID of $+20 \mathrm{~dB}$ than it was at higher or lower IIDs. The differential effects of bicuculline at the various IIDs suggest that GABAergic inhibition shapes binaural facilitation and maximum inhibition in different ways. Using the discharge rates in the predrug condition as a baseline, we interpolated from the monaural rateintensity function that tone bursts at $20 \mathrm{~dB}$ evoked 29 spikes (Fig. 13, top left panel). Under binaural conditions, the intensity at the right (excitatory) ear was held constant at $20 \mathrm{~dB}$. With an IID of $+40 \mathrm{~dB}$, right ear stronger, 34 spikes were elicited (Fig. 13, top right panel), a discharge rate similar to that interpolated from the monaural rate-intensity function. When the intensity at the left ear was increased by $20 \mathrm{~dB}$ so that the IID was $+20 \mathrm{~dB}$, right ear stronger, the discharge rate increased to 58 spikes and thus the cell expressed facilitation. Further increases in the intensity at the left (inhibitory) ear then caused a reduction in discharge rate to 24 spikes; the predrug maximum inhibition was $59 \%$. With $20 \mathrm{nA}$ of bicuculline (Fig. 13, middle panels), the discharge rates at IIDs of $+40 \mathrm{~dB}$ and $+20 \mathrm{~dB}$ were virtually the same as the predrug condition, and thus the facilitation was also unchanged. However, the discharge rate at an IID of $-20 \mathrm{~dB}$, left ear stronger, was slightly elevated. As a

\footnotetext{
Figure 12. Binaural response properties for a neuron that showed progressive reduction and eventual elimination of maximum inhibition and binaural facilitation with increasing dosages of bicuculline. Bicuculline essentially removed the influence of the left (inhibitory) ear and transformed the unit from an EI/f into a monaural cell. Values of maximum inhibition and binaural facilitation for predrug and bicuculline conditions are shown next to each graph. Bottom panel shows monaural rate-intensity function with $20 \mathrm{nA}$ of bicuculline to illustrate that the discharge rates evoked with binaural stimulation were not saturated.
} 
result, the maximum inhibition declined from a predrug value of $59-46 \%$.

When the ejection current of bicuculline was increased to 40 nA, the differential effects at $+40 \mathrm{~dB}$ IID and $+20 \mathrm{~dB}$ IID became apparent. The discharge rate increased to about 51 spikes at an IID of $+40 \mathrm{~dB}$, a rate close to the rate evoked by a monaural $20 \mathrm{~dB}$ stimulus presented to the right (excitatory) ear that we interpolated from the rate-intensity function. The significant feature is that the discharge rate at the facilitated IID ( $+20 \mathrm{~dB}$, right ear stronger) remained constant at $\sim 60$ spikes, resulting in a marked decrease in binaural facilitation; in the predrug condition, the response rate increased by $61 \%$ when the IID changed from $+40 \mathrm{~dB}$ to $+20 \mathrm{~dB}$, whereas the increase was only $20 \%$ with $40 \mathrm{nA}$ of bicuculline. We also point out that a discharge rate of 60 spikes with bicuculline was below the cell's saturated response rate, as revealed by the rate-intensity function shown in the bottom left panel of Figure 13. As the intensity at the left (inhibitory) ear was increased so that the IID was $-20 \mathrm{~dB}$ (left ear stronger), the cell no longer was as strongly inhibited as it had been in the predrug condition and the maximum inhibition declined to $30 \%$. Thus, the reduction in the facilitation was due to a dose-dependent increase in the discharge rate evoked by a $20 \mathrm{~dB}$ monaural tone burst, a rate that was virtually the same as the rate evoked with binaural stimulation at an IID of $+40 \mathrm{~dB}$, right ear stronger. That rate increase progressively reduced the difference in discharge rates evoked by IIDs of $+40 \mathrm{~dB}$ and $+20 \mathrm{~dB}$, thereby reducing the facilitation as well. The reduction in maximum inhibition, in contrast, was apparently due to a progressively greater blockage of the inhibition evoked by relatively high sound intensities at the left (inhibitory) ear. In short, there was a dose-dependent reduction of both maximum inhibition and binaural facilitation that was apparently due to the effects of bicuculline on different aspects of the IID function. Whether the maximum inhibition and facilitation would have been completely abolished with higher dosages of bicuculline is unclear since $40 \mathrm{nA}$ was the largest ejection current that was employed with this cell.

Finally, the unit in Figure 14 also illustrates a dose-dependent decline of both maximum inhibition and binaural facilitation. In this unit, however, the progressive decline in both measures reached a plateau at $10 \mathrm{nA}$ of bicuculline; neither the maximum inhibition nor the facilitation appeared to decline further when the bicuculline ejection current was raised to $20 \mathrm{nA}$, suggesting that the full reduction of these binaural properties had been achieved. The lowest panels in Figure 14 show that within 7 min after terminating the application of bicuculline, both the binaural facilitation and maximum inhibition recovered. The recovered rate-level and IID functions are particularly noteworthy because the shapes of the functions were so similar to the predrug functions. They differed only in response magnitude: the maximum discharge rate in the predrug IID function was 27 spikcs, whercas the recovered maximum discharge rate was 54 spikes. These features strongly suggest that the reductions in facilitation and maximum inhibition in the $5 \mathrm{nA}$ bicuculline condition were not simply due to an overall increase in response magnitude. If they were, then the shape of the recovered IID function where the maximum discharge rate was 54 spikes should not have been similar to either the predrug function (maximum discharge rate of 27 spikes) or the $5 \mathrm{nA}$ bicuculline function (maximum discharge rate of 72 spikes), but rather should have been intermediate between the two functions. For this unit, then GABAergic inhibition apparently contributed partially but not

\section{Right (Excitatory) Ear Both Ears}
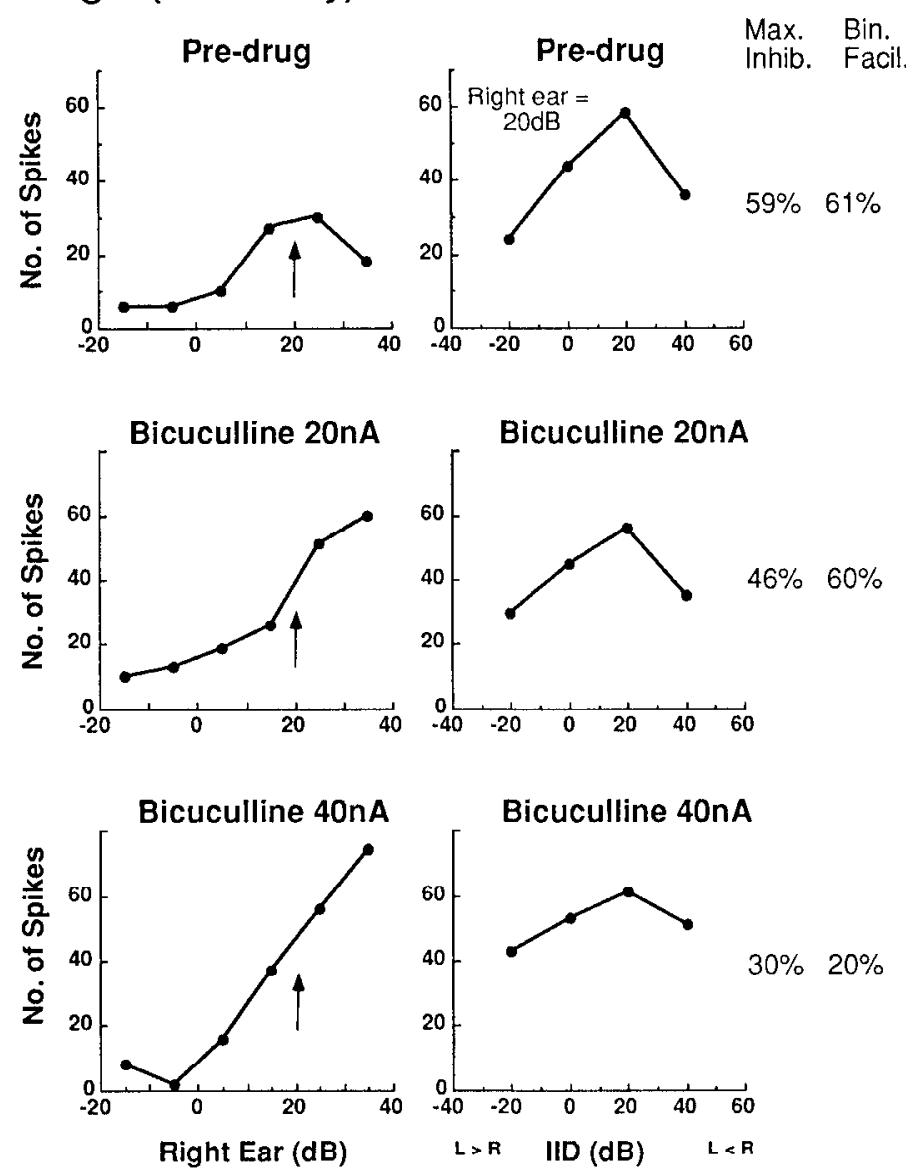

Figure 13. An EI/f unit that showed dose-dependent effects on maxinum inhibition and binaural facilitation. The predrug rate-intensity function and IID function are shown in the top panels. The rate-intensity and IID functions obtained with $20 \mathrm{nA}$ of bicuculline are shown in the middle panels, and the same functions obtained with $40 \mathrm{nA}$ of bicuculline are shown in the bottom panels. The arrows indicate the approximate response rates evoked by $20 \mathrm{~dB}$ tone bursts presented monaurally. These rates were similar to the rates evoked with binaural stimulation when the intensity at the left (ipsilateral) ear was low (with the most positive IIDs presented). Values of maximum inhibition and binaural facilitation for predrug and bicuculline conditions are shown next to each graph. Since this unit was not tested directly with $20 \mathrm{~dB}$ monaural stimulation, binaural facilitation was determined from the IID functions as the percentage of response increase from $+40 \mathrm{~dB}$ IID to $+20 \mathrm{~dB}$ IID. Note the different scale for number of spikes in each panel.

entirely to both the maximum inhibition and binaural facilitation.

\section{Discussion}

The purpose of this report is to examine how the $G \Lambda B \Lambda_{A}$ receptor antagonist bicuculline affected three measures of binaural response properties of excitatory/inhibitory neurons in the inferior colliculus. There are three main findings. First, bicuculline substantially reduced or eliminated the maximum inhibition in about $40 \%$ of the cells. Second, bicuculline changed the IID of the $50 \%$ point in more than half of the cells that retained their predrug maximum inhibition. Third, bicuculline affected binaural facilitation in $80 \%$ of EI/f cells, and in more than half of the EI/f cells it totally eliminated the facilitation. These findings were obtained with a limited stimulus set in that the intensity 


\section{Right (Excitatory) Ear}
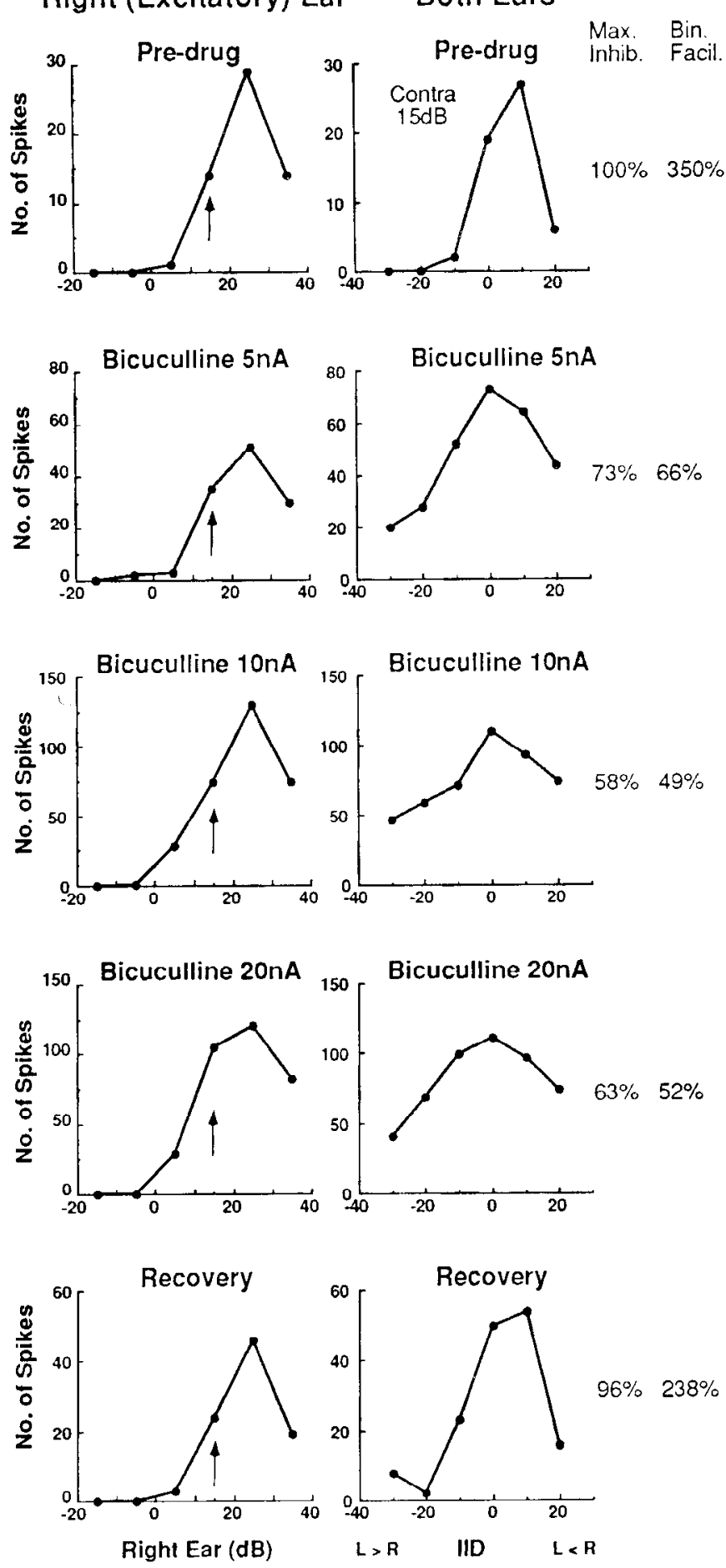

Figure 14. Neuron in which bicuculline had dose-dependent effects on maximum inhibition and binaural facilitation with small ejection currents. The effects of bicuculline apparently reached a saturation level at about $10 \mathrm{nA}$ such that higher dosages produced no additional effects. Bottom graphs show recovery of EI/f properties. Arrows indicate the response rates generated by $15 \mathrm{~dB}$ tone bursts presented monaurally. Values of maximum inhibition and binaural facilitation for predrug and bicuculline conditions are shown next to each graph. Note the different scale for number of spikes in each panel. at the excitatory ear was held constant at $10-20 \mathrm{~dB}$ above threshold. Hence, our results do not describe the full range of binaural properties since these properties arc in some cells influenced by the absolute intensity at the excitatory ear (e.g., Semple and Kitzes, 1987; Wenstrup et al., 1988a; Irvine and Gago, 1990). However, by using only one excitatory intensity, we were able to assess the effects of increasing intensity at the inhibitory ear on a constant influence exerted by the other ear without introducing the complications of the additional circuits recruited by higher sound intensities at the excitatory ear. The information obtained from this procedure also allowed us to propose circuits that could account for the effects that we observed after blocking GABAergic inhibition. Below, we first discuss the types of circuits that are likely to be involved in creating the three binaural properties and the likely origins of those GABAergic circuits. We then discuss the implications of the bicuculline-induced changes in binaural inhibition for the processing of information relevant for the localization of a sound source.

\section{Maximum inhibition}

The blockage of GABAergic inputs with bicuculline had a wide range of effects on maximum inhihition. At one extreme are the 52 cells in which bicuculline had minimal or no effects. Since bicuculline clearly blocked GABAergic inputs evoked by stimulation of either ear, as illustrated by the changes in response rates, rate-intensity functions, and most importantly, $50 \%$ points, it appears that GABAergic innervation at the level of the colliculus was not involved in the generation of the maximum inhibition in these cells. Rather, the maximum inhibitions of these neurons either were created in a lower binaural nucleus such as the latcral superior olive and imposed upon the collicular cells via an excitatory projection or were formed in the colliculus by glycinergic inhibition.

At the other extreme are the 14 cells whose maximum inhibitions were greatly reduced or eliminated by bicuculline. Our interpretation of this result is that maximum inhibition is created in the left colliculus by the convergence of an excitatory input from the right (excitatory) ear and a GABAergic input from the left (inhibitory) ear. When we applied bicuculline to these cells, the drug eliminated the maximum inhibition by allowing the responses evoked by sound at the right (excitatory) ear to be expressed in the presence of stimulation to the left (inhibitory) ear that would normally inhibit those discharges.

Intermediate between the two extreme effects on maximum inhibition are the 17 cells in which bicuculline caused moderate changes in maximum inhibition. We point out that the change in maximum inhibition that we observed may have underestimated the full effects of the GABAergic inhibition. The reason is that the effects of bicuculline on most response properties including maximum inhibition were often dose dependent ( $\mathrm{Pol}-$ lak and Park, 1993). Since we used only one low dose of bicuculline on most cells, it seems likely that even larger changes in maximum inhibition may have been revealed had we employed higher doses of bicuculline.

However, in a few cells we are more confident that the moderate influence of GABAergic inhibition on maximum inhibition would not have increased with higher doses of bicuculline. We say this because we tested five cells that had a moderate change in maximum inhibition with more than one dosage of bicuculline. In two of those cells, the moderate change in maximum inhibition obtained with the lowest dosage did not increase when a higher dosage of bicuculline was applied, indi- 
cating that the full reduction in maximum inhibition had been achieved (e.g., Fig. 14). This suggests that in some cells GABAergic inputs activated by the left (ipsilateral) ear enhance a preexisting inhibition established in a lower binaural center, or add to an inhibition generated in the colliculus with glycinergic inhibition.

\section{$50 \%$ points}

Bicuculline caused the $50 \%$ point IID to change in more than half (30) of the cells in which bicuculline had little or no effect on maximum inhibition. In the majority of these cells, bicuculline caused their $50 \%$ points to shift to more negative IIDs such that a higher intensity at the left (inhibitory) ear was required to suppress the response rate by $50 \%$. In other words, the normal predrug $50 \%$ points were closer to an IID of zero, or in some cases to IIDs in which sound at the right (excitatory) ear was stronger.

The simplest interpretation of such shifts is that in the normal condition there are at least two inhibitory circuits that form the IID function in the collicular cell, one of which is GABAergic (Fig. 15). One circuit initially creates the excitatory/inhibitory property of the cell by the convergence of an excitatory projection from the right (contralateral) ear and an inhibitory projection from the other ear. This circuit establishes both a maximum inhibition and a $50 \%$ point IID that is achieved when the intensity at the left (ipsilateral) ear is substantially greater than the intensity at the right ear. The circuit occurs either in a lower nucleus such as the lateral superior olive, and then imposes the IID function on the collicular cell via an excitatory projection as in Figure 15, or it occurs in the colliculus via glycinergic inhibition. In either case, this circuit is not affected by iontophoresis of bicuculline. The second circuit is GABAergic and converges upon the same collicular cell that the first circuit innervates. The GABAergic circuit is driven only by stimulation of the left (ipsilateral) ear and has a lower absolute threshold than the inhibitory component of the first circuit. Thus, the effect of the GABAergic circuit is to change the IID function at the colliculus, where it causes the discharge rate to decline with lower intensities at the left ear than did the IID function created in the first circuit. In short, the resultant IID function due to the summation of these circuits has a $50 \%$ point that is shifted to a more positive IID that requires less intensity at the ipsilateral ear for inhibition but has the same maximum inhibition that was initially established in the first circuit. The effect of bicuculline was to remove the influence of the GABAergic circuit, thereby allowing the maximum inhibition and $50 \%$ point IID of the first circuit to be expressed by the collicular cell.

\section{Binaural facilitation}

Perhaps the most intriguing result of this study is that bicuculline eliminated facilitation in more than half of the EI/f cells (14 of 25 ). Thus, in many cells GABAcrgic inhibition plays an important role in the generation of the "facilitation," although the facilitation was apparently produced partially or completely by other mechanisms in those $\mathrm{EI} / \mathrm{f}$ cells in which facilitation was unaffected or only partially reduced with bicuculline. For purposes of clarity, we outline a circuit for an $\mathrm{EI} / \mathrm{f}$ cell in which GABAergic inhibition shapes the facilitated response but not the maximum inhibition or IID of the $50 \%$ point (Fig. 16). The circuit has two requirements. The first is that the EI/f collicular cell is innervated by two EI cells. One of the EI cells provides excitation (cell L in Fig. 16B), and the other is GABAergic and

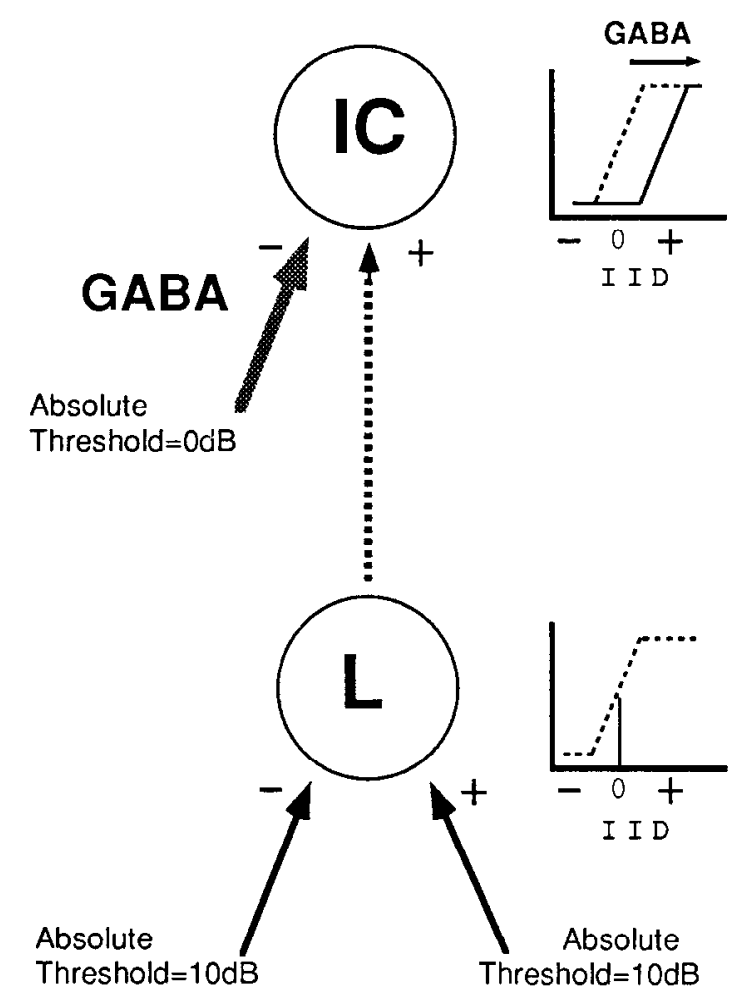

\section{Left Ear}

\section{Right Ear}

Figure 15. Hypothetical circuitry to explain how an EI neuron in the inferior colliculus $(I C)$ could have a shift in $50 \%$ point IID but no change in maximum inhibition. In this circuit, the IID function, and hence the $50 \%$ point and maximum inhibition, are established in a cell below the inferior colliculus (cell $L$ ) by a convergence of excitatory inputs from one ear and inhibitory inputs from the other ear. The absolute thresholds of both the excitatory and inhibitory inputs are equal for this lower unit $(10 \mathrm{~dB})$, which results in a $50 \%$ point at an IID of $0 \mathrm{~dB}$. The IID function of the lower cell (cell $L$ ) is shown in the lower right with broken lines. The properties of the IID function are then imposed on the collicular cell via an excitatory projection (broken arrow). An inhibitory GABAergic input (thick arrow on left) innervates the same collicular neuron. The GABAergic input is excited only by the left (inhibitory) ear and has a lower absolute threshold than the inhibitory component below the colliculus. The absolute threshold of the GABAergic inputs in this example is $0 \mathrm{~dB}$. The result is that the GABAergic input inhibits the collicular cell at lower IIDs than would otherwise be inhibitory. Hence, the IID function shifts to right, as indicated by the solid line in the IID function shown in the upper right. Blocking the GABAergic inputs to the colliculus with bicuculline reveals the $50 \%$ point IID and maximum inhibition imposed by cell $L$. Thus, the IID function and the IID at the $50 \%$ point of the collicular cell shift to the left with bicuculline, as indicated by the broken line in the upper IID function, while the maximum inhibition is unchanged.

thus is inhibitory to its collicular target (cell G in Fig. 16D). Both cells are excited by sound at the right (contralateral) ear and inhibited by sound at the left ear. The second requirement is that the GABAergic EI cell, the G cell, needs a higher intensity at the left (inhibitory) ear to achieve 50\% inhibition compared to the $L$ cell. With binaural stimulation in which sound at the right (excitatory) ear is more intense than at the left (inhibitory) ear, both the $L$ and $G$ cells are excited but receive little or no inhibition. Under these conditions, the $\mathrm{L}$ cell provides an excitatory drive to the collicular cell (broken line in Fig. 16), but the discharge rate of the collicular cell is reduced due to the 


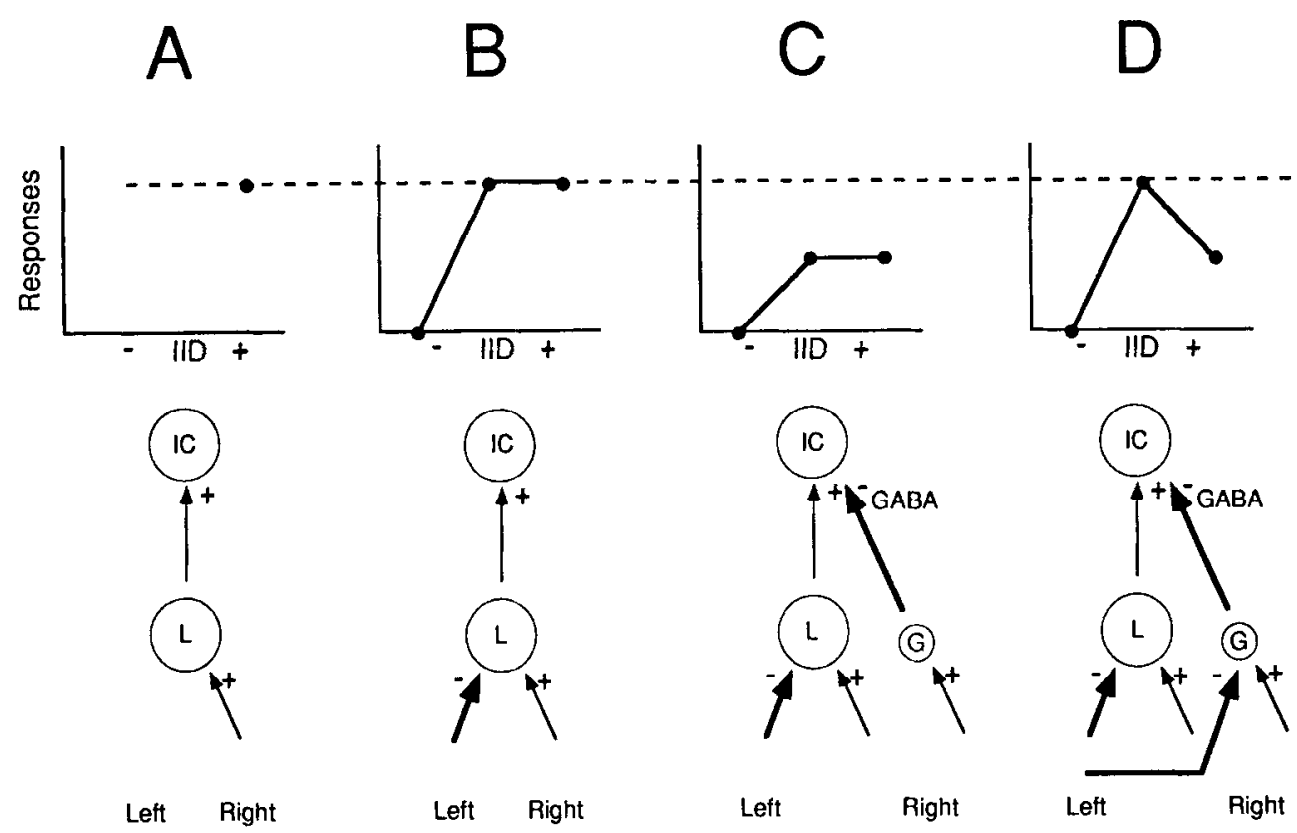

Figure 16. Step-by-step construction of a hypothetical circuit to explain how GABAergic inputs could create binaural facilitation. Thick arrows represent inhibitory projections, and thin arrows are excitatory projections. $A$, We begin with an excitatory input from the right ear that makes a synaptic connection with a cell in a lower nucleus (cell L). Sound intensity at the right ear $10 \mathrm{~dB}$ above threshold evokes a certain discharge rate. That discharge rate is then imposed on the inferior colliculus cell $(I C)$ via an excitatory projection. The discharge rate of the collicular cell is shown by the circle in the top graph. B, We next add an inhibitory input from the left ear to cell $L$, thereby making it EI with properties similar to an EI cell in the contralateral lateral superior olive. The EI properties of cell $\mathrm{L}$ are also expressed by the collicular cell, shown as the IID function in the top panel. $C$, A GABAergic input to the collicular cell that originates from cell $G$ is added next. The GABAergic cell (cell $G$ ) receives excitation from the right ear. When sound is presented to the right ear, it simultaneously evokes an excitation via cell $L$ and an inhibition in the collicular cell via cell $G$. The inhibition from cell $G$ reduces the overall discharge rate of the collicular cell. Adding sound to the left ear generates an IID function with a lower overall response rate than cell $L$ but has the same maximum inhibition. $D$, Lastly, an inhibitory input evoked by the left ear is added to cell $G$, making it EI. Cell $G$ has a lower $50 \%$ point IID than cell $L$. Sound at the right ear alone at $10 \mathrm{~dB}$ above threshold or with a subthreshold intensity at the left ear evokes the same reduced discharge rate as described for $C$. The reason is that sound at the right ear drives both cell $L$ and cell $G$, thereby simultaneously evoking an excitation and an inhibition in the collicular cell. The critical event occurs when the intensity at the left ear is increased slightly such that the inhibitory input is above threshold at cell $G$ but is still below threshold for cell $L$. At this point, then, cell $L$ provides the same excitatory drive to the colliculus as it did with a weaker sound at the left ear, but since cell $G$ is inhibited and thus no longer imparts an inhibition at the colliculus, the discharge rate of the collicular cell increases and expresses facilitation. As the intensity at the left ear increases, inhibitory inputs continue to suppress cell $G$, but in addition, it now also suppresses discharges in cell $L$. As the discharge rate of cell $\mathrm{L}$ falls to zero, so does the discharge rate of the collicular cell. The effect of bicuculline (not shown) on this circuit is to block the activity of cell $G$. Hence, the response rate increases and the collicular'cell simply expresses the EI property of the lower cell, as shown in $B$.

inhibition by the $\mathrm{G}$ cell (Fig. 16C). The key event occurs with slightly higher IIDs around $0 \mathrm{~dB}$. These IIDs are sufficient to inhibit the $G$ cell but are not yet large enough to inhibit the $L$ cell. Thus, the $\mathrm{L}$ cell continues to excite the collicular cell, but now the discharge rate of the collicular cell is enhanced because it no longer receives inhibition from the $G$ cell (Fig. 16D). In other words, the GABAergic inhibition evoked by the right (contralateral) ear is disinhibited when moderately intense sound is presented to the left ear, and the disinhibition is expressed as a facilitation. As the sound intensity at the left (inhibitory) ear increases, the threshold for the inhibitory input to the $\mathrm{L}$ cell is reached and then exceeded. Consequently, the excitatory drive of the $\mathrm{L}$ cell is progressively reduced, which in turn reduces the discharge rate of the collicular cell (Fig. 16D). We point out that the circuit could work equally well if the $L$ cell were replaced by an excitatory projection from the right (contralateral) ear and a glycinergic inhibitory projection from the left ear that converged at the colliculus.

With this circuit, the application of bicuculline eliminates the GABAergic inhibition provided by the $\mathrm{G}$ cell. The removal of GABAergic inhibition allows an increased response rate to be evoked by the sound at the right (contralateral) ear, and the increase is not dependent on the sound intensity at the left ear.
Thus, increasing the intensity at the left ear no longer evokes a facilitation, and the IID function will be generated only by the $\mathrm{L}$ cell as in Figure $16 \mathrm{~B}$. The maximum inhibition and IID of the $50 \%$ point are not affected because they are not produced by GABAergic inhibition at the colliculus.

It should be noted, however, that in some EI/f cells bicuculline not only eliminated the binaural facilitation but also significantly reduced or eliminated entirely their maximum inhibitions. Our interpretation of these changes is that the binaural facilitation was generated by a mechanism similar to that described above, but in these cells the maximum inhibition was either generated entirely by an additional GABAergic circuit that innervates the colliculus (e.g., the unit in Fig. 12) or was only partially created in a lower nucleus and was reinforced by GABAergic innervation of the colliculus (e.g., the unit in Fig. 14). It would appear, then, that the GABAergic circuits can act independently of each other or can function simultaneously to influence more than one binaural property.

\section{Possible origins of GABAergic circuits}

Using the known features of the EI projection system, we speculate on the possible origins of the GABAergic circuits described above. Previous studies have revealed three major sources of 
GABAergic innervation of the inferior colliculus: (1) collicular neurons that act locally, (2) the left (ipsilateral) dorsal nucleus of the lateral lemniscus, and (3) the right (contralateral) dorsal nucleus of the lateral lemniscus (Fig. 1).

We turn first to those neurons that act within the colliculus, of which there are two types: interneurons that only act intrinsically, and principal cells whose axons project to higher nuclei and provide collaterals to other collicular cells (Rockel and Jones, 1973a,b; Morest and Oliver, 1984; Oliver and Morest, 1984; Zook et al., 1985; Oliver et al., 1991; Saldana and Merchan, 1992). Immunocytochemical studies in a number of mammals, including the mustache bat (Pollak and Winer, 1989; Pollak et al., 1992; Vater ct al., 1992), demonstrate that a substantial portion of collicular cells are GABAergic, and these cells include both principal cells and small cells that presumably are intrinsic (Adams and Wenthold, 1979; Mugniani and Oertel, 1985; Thompson et al., 1985; Moore and Moore, 1987; Roberts and Riback, 1987a,b; Oliver et al., 1988; Caspary et al., 1990). It should be noted that with rare exception, all collicular cells are excited by the right (contralateral) ear (e.g., Roth et al., 1978; Semple and Aitkin, 1979; Aitkin, 1986; Irvine, 1986; Wenstrup et al., 1986, 1988a,b). Thus, these neurons could provide GABAergic inhibition to other collicular cells and shape the wide variety of GABA-mediated monaural response properties that have been reported in previous studies (Faingold et al., 1989, 1991; Yang et al., 1992; Pollak and Park, 1993). It seems unlikely, however, that GABAergic collicular cells were involved in the formation of maximum inhibition or in the $50 \%$ point shifts. Thesc propertics require that the GABAergic cells be activated by stimulation of the left (ipsilateral) ear, whereas monaural collicular cells are unaffected and EI collicular neurons are inhibited by the left (ipsilateral) ear. On the other hand, we proposed in the previous section that binaural facilitation is produced by a GABAergic EI cell, the G cell in Figure 16, that is inhibited by the left (ipsilateral) ear. Since some GABAergic collicular cells are presumably EI and would be inhibited by sound at the left (ipsilateral) ear, the $G$ cell in Figure 16 could be a GABAergic EI collicular cell that acts locally on other EI cells.

Another type of collicular cell that may have affected binaural inhibition is the commissural cells that provide projections from the colliculus on the opposite side (Adams, 1980; Zook and Casseday, 1982; Ross et al., 1988; Ross and Pollak, 1989; Hutson et al., 1991). Although the participation of commissural cclls cannot be ruled out, commissural fibers project sparsely to the EI region of the mustache bat's inferior colliculus (Ross and Pollak, 1989), and it is unknown whether or not they are GABAergic.

The dorsal nuclei of the lateral lemniscus are also prime sources of GABAergic innervation since their cells are predominantly if not entirely GABAergic (Adams and Mugniani, 1984; Mugniani and Oertel, 1985; Thompson et al., 1985; Robcrts and Riback, 1987a,b; Pollak and Winer, 1989; Glendenning et al., 1992; Pollak et al., 1992; Vater et al., 1992). For reasons explained below, the left and right dorsal nuclei can influence monaural and binaural properties differently. Studies indicate that high-frequency cells in the dorsal nuclei are excitatory/ inhibitory (Brugge et al., 1970; Covey and Casseday, 1991; Markovitz and Pollak, 1993). This suggests that neurons in the left dorsal nucleus are excited by stimulation of the right (contralateral) ear and inhibited by stimulation of the left (ipsilateral) ear, similar to EI cells in the left colliculus (Fig. 1). As was the case for intrinsic collicular neurons, the response properties suggest that the projections from the left (ipsilateral) dorsal nucleus could influence monaural response properties and binaural facilitation of cells in the left colliculus. Iowever, they should have little or no influence on the maximum inhibitions or $50 \%$ points of collicular neurons. The reason is that the GABAergic cell or cells responsible for maximum inhibition or for shifting the IID of the $50 \%$ point need to receive excitation from the left (ipsilateral) ear in order to inhibit their target in the colliculus. However, cells in the left dorsal nucleus of the lateral lemniscus are probably not excited but rather are most likely inhibited by stimulation of the left (ipsilateral) ear, and thus are unavailable to provide inhibition to the colliculus with binaural stimuli.

The most likely source of GABAergic innervation that could affect maximum inhibitions and IIDs of $50 \%$ points is the right (contralateral) dorsal nucleus of the lateral lemniscus (Fig. 1). Not only does the right dorsal nucleus provide the strongest GABAergic inputs to the left colliculus (Shneiderman et al., 1988; Markovitz and Pollak, 1993), but its cclls arc cxcitcd by stimulation of the left ear and thus are in a favorable position to exert a potent influence on binaural inhibition in the left inferior colliculus. This role is further supported by a recent study by Li and Kelly (1992a) in the rat. They showed that pharmacologically inactivating the dorsal nucleus reduced or eliminated binaural inhibition in a substantial number of EI neurons in the contralateral colliculus.

\section{Comparisons with previous studies}

The shaping of binaural response properties by GABAergic inhibition is apparently a general feature of auditory processing in the midbrain. Fujita and Konishi (1991), for example, showed that GABA sharpens selectivity for interaural time disparities in the owl's auditory pathway. Yin and Chan (1990) showed that interaural time disparity functions in the cat are sharper in collicular cells than in the medial superior olive. It seems significant that the difference between interaural time disparity functions in the two nuclei of the cat was similar to the sharpening of interaural time disparity functions seen in the owl's inferior colliculus with bicuculline. This suggests that a process similar to that in the barn owl also occurs in the mammalian auditory system, although it has not been shown that GABAergic inhibition underlies such changes in the cat's inferior colliculus.

There are also several recent studies that support the hypothesis that GABAergic inhibition is involved in processing IIDs in the inferior colliculus. Consistent with our results, Faingold and his colleagues (Faingold et al., 1989, 1991) also found that bicuculline markedly reduced the maximum inhibition of EI cells in the rat's inferior colliculus. As mentioned previously, $\mathrm{Li}$ and Kelly (1992a) showed that the maximum inhibition in a substantial number of EI units in the rat's inferior colliculus could be reduced or eliminated by inactivating the contralateral dorsal nucleus of the lateral lemniscus, suggesting that GABAergic inhibition underlies the maximum inhibition of the units from which they recorded.

\section{Relevance for sound localization}

Each of the three binaural response properties we studied influences the azimuthal receptive fields of $60 \mathrm{kHz}$ collicular neurons (Fuzessery and Pollak, 1985; Wenstrup et al., 1988b; Fuzessery et al., 1990). These influences are most easily visualized by first 
IID Function

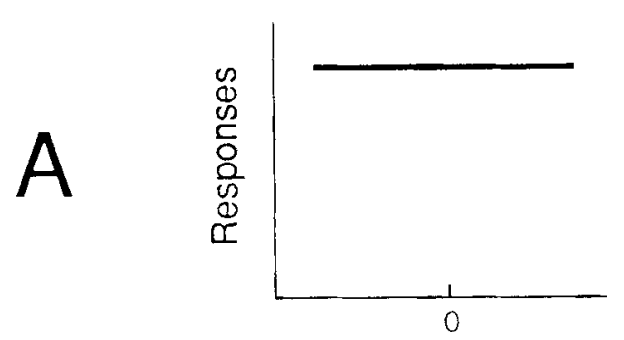

Figure 17. Influence of $50 \%$ point IID, maximum inhibition, and binaural facilitation on receptive fields of collicular neurons. Stylized azimuthal receptive fields and IID functions are shown for a monaural neuron $(A)$, EI neurons $(B-D)$, and an $\mathrm{EI} / \mathrm{f}$ neuron $(E)$. Receptive fields show regions of space along the azimuth where sounds at varjous intensities elicit discharges. Response magnitude is indicated by shad ing, where the darkest areas represent $75-100 \%$ of maximum discharge rate, dark gray areas represent $50-74 \%$ of maximum discharge rate, and light gray. areas represent $25-49 \%$ of maximum discharge rate. $A$, Receptive field of a monaural neuron. $B$, Receptive ficld of an EI neuron with $100 \%$ maximum inhibition and a $50 \%$ point IID of $0 \mathrm{~dB}$ indicated by the broken line in the IID function. The effect of the inhibition evoked by the left ear is to limit the regions of the left sound field from which discharges could be evoked. $C$. Effect of a change in $50 \%$ point IID. This neuron also has $100 \%$ maximum inhibition but a different (more negative) IID at the $50 \%$ point than the neuron in $B$. Note the encroachment of the receptive field across the midline and in to the left acoustic field. $D$, Effect of change of maximum inhibition. The $50 \%$ point IID is $0 \mathrm{~dB}$, as it is in $B$ above, but the maximum inhibition is reduced to $75 \%$. Higher sound intensities located in the left sound field now evoke discharges. $E$, Receptive field of an EI/f unit. Note that the IID at the $50 \%$ point is the same as the EI neuron in $C$ above, as is the receptive field border in the left (ipsilateral) sound field. The facilitation at $0 \mathrm{~dB}$ IID, however, results in a region of maximal firing focused directly ahead. Receptive fields are for $60 \mathrm{kHz}$ units with monotonic rate-intensity functions. Construction of EI receptive fields is based on the model of Wenstrup et al. (1988b), and construction of EI/f receptive field is based on Fuzessery et al. $(1990)$.
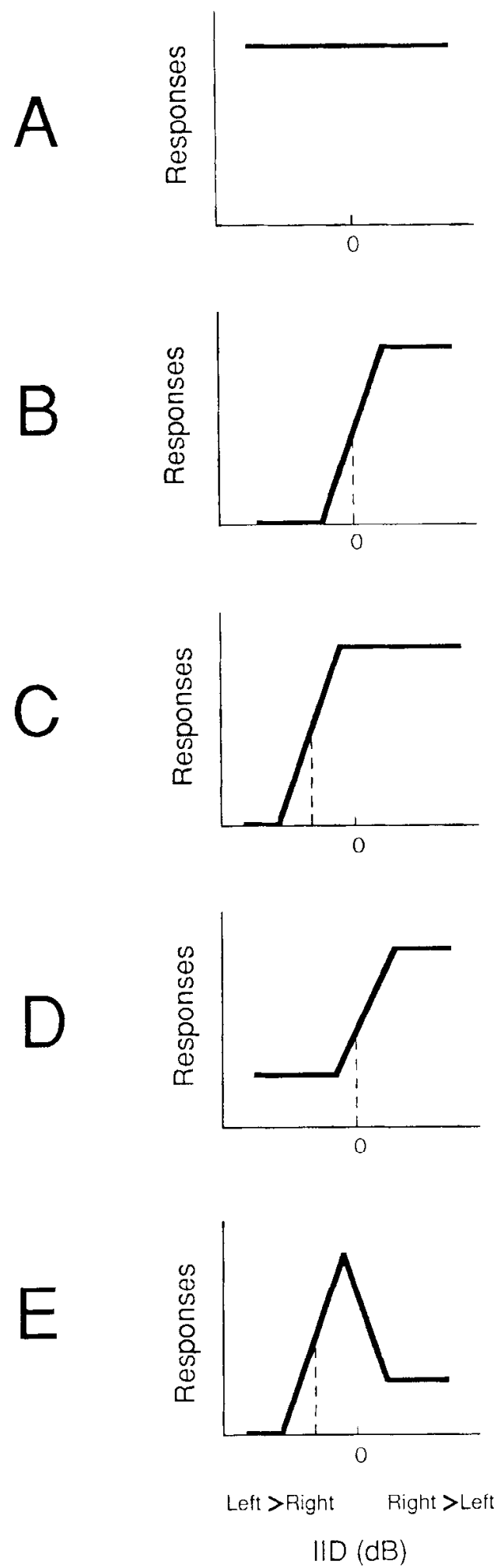

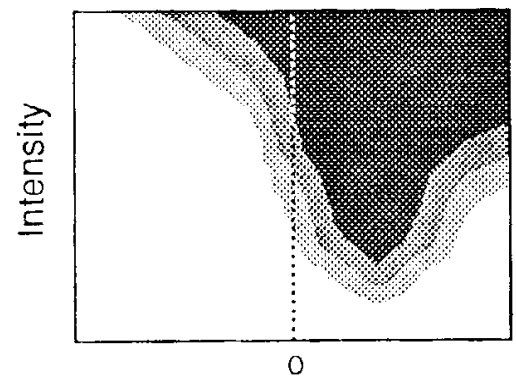

Receptive Field
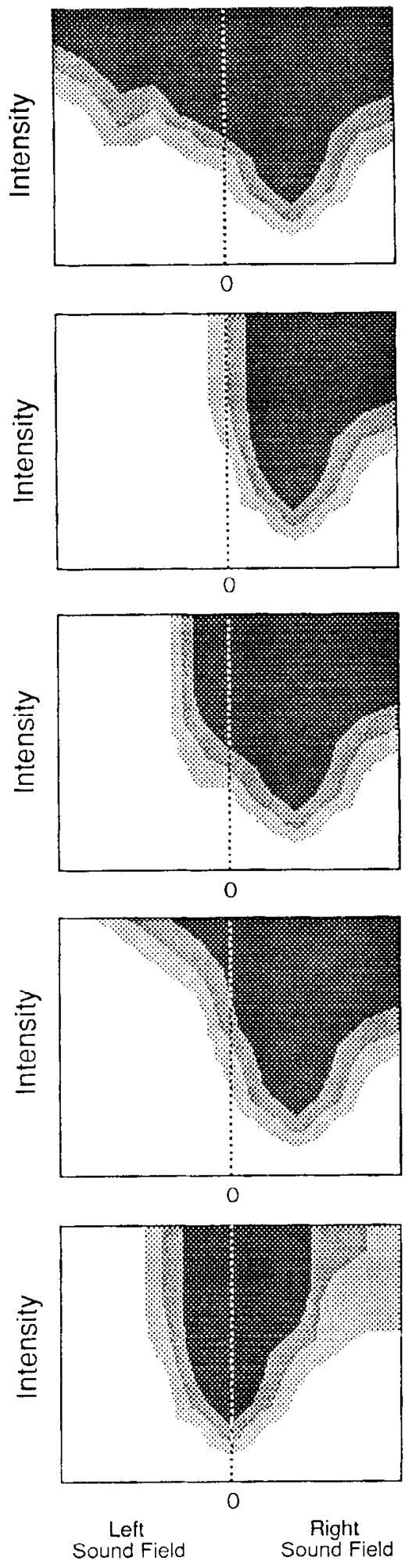

Sound Location (degrees) considering the azimuthal receptive field of a $60 \mathrm{kIIz}$ monaural neuron in the left inferior colliculus. In monaural neurons, sound from all locations in either the left or right sound field evoke maximum discharge rates (Fig. 17A) (Fuzessery and Pollak, 1985;
Wenstrup et al., 1988b). The shape of the receptive field is due to shadowing and the directional properties of the ears, and thus sound intensity in the left (ipsilateral) field must be greater than sound intensity in the right (contralateral) field to cvoke the 
same discharge rate. The consequence of adding an inhibitory projection from the left (ipsilateral) ear is that when the sound source is in the left acoustic field and is sufficiently intense, it turns on the inhibitory projection, which then suppresses discharges. The net result is that the receptive fields of $60 \mathrm{kHz}$ El collicular units are characterized by a border in space (Fig. 17B) (Fuzessery and Pollak, 1985; Wenstrup et al., 1988b). Sounds emanating from one side of the border, which correspond to more intense sound at the right (excitatory) ear, evoke a more or less strong discharge rate depending upon the signal intensity. Sounds emanating from the other side of the border corresponding to locations closer to the left (inhibitory) ear evoke little or no discharges. The border is the location in space at which the discharge rate changes from one that is fairly vigorous to a much lower rate or a complete inhibition. For the unit in Figure $17 B$, the border is close to the midline.

It is of importance that the IID at the $50 \%$ point is an accurate predictor of the receptive field border in $60 \mathrm{kHz}$ EI cells (Fig. 17B,C) (Fuzessery and Pollak, 1985; Wenstrup et al., 1988b). Thus, the receptive fields of units that have negative IIDs at the $50 \%$ points (left ipsilateral ear more intense) have borders in the left (ipsilateral) sound field. Thesc units respond to sound from anywhere in the right (contralateral) acoustic field and only in certain regions of the left (ipsilateral) acoustic field near the midline (Fig. $17 \mathrm{C}$ ). The receptive fields of units with progressively more positive IIDs at $50 \%$ points have borders that are shifted toward the midline or into the right (contralateral) sound field. Units with $50 \%$ point IIDs around $0 \mathrm{~dB}$ are inhibited by sound in the ipsilateral sound field and respond most strongly or only when the sound is at and beyond the midline. Units with positive IIDs at their $50 \%$ points respond only when sounds emanate from the right (contralateral) acoustic field.

While the IID at the $50 \%$ point determines the border of the unit's receptive field, the binaural feature that determines the degree to which the discharge rate changes beyond the receptive field border is the maximum inhibition (Fig. 17D) (Wenstrup et al., 1988b). The discharge rate beyond the border declines in proportion to the unit's maximum inhibition. EI units whose maximum inhibition is $100 \%$ are completely inhibited by sounds in the left (ipsilateral) sound field, whereas the discharge rate declines markedly but is not completely suppressed in units with lesser maximum inhibitions (compare Fig. 17B,D).

The receptive fields of EI/f cells are variations of the fields of EI cells (Fig. 17E) (Fuzessery and Pollak, 1985; Fuzessery et al., 1990). Like EI cells, they respond poorly or not at all to sounds located in the left (ipsilateral) acoustic field, and their borders are determined by the IID at their $50 \%$ point. Unlike EI cells, the discharge rates of EI/f cells are enhanced for sound locations that generate the IIDs at which they are facilitated. The IIDs producing facilitation are usually at or close to $0 \mathrm{~dB}$ and thus occur around the midline. EI/f cells, then, respond most vigorously to sounds located directly ahead as a consequence of the binaural facilitation.

The $50 \%$ point IIDs of $60 \mathrm{kHz}$ EI cells are systematically ordered in the mustache bat's inferior colliculus (Wenstrup et al., 1985, 1986). EI neurons with negative $50 \%$ point IIDs (i.e., neurons requiring a more intense sound at the left ear than at the right ear to produce $50 \%$ inhibition) are located in the dorsal EI region. More ventral EI neurons display a progressive shift to more positive $50 \%$ point IIDs. The most ventral EI neurons have the highest, most positive $50 \%$ point IIDs: they are suppressed by sound intensities at the left ear that are less intense than the sounds at the right (contralateral) ear. This arrangement forms a computational map of the IIDs generated by $60 \mathrm{kHz}$ signals at the ears, and has important implications for the way in which sound location is represented in the auditory system (Pollak et al., 1986; Wenstrup et al., 1986, 1988b; Pollak and Casseday, 1989; Pollak, 1992).

A question of some interest concerns the site at which the map is initially generated. We had previously thought that the map is most likely first created in the lateral superior olive. Our reasoning was that since lateral superior olive cells display a wide range of 50\% point IIDs (Boudreau and Tsuchitani, 1968; Sanes and Rubel, 1988; Covey et al., 1991), it seems likely that the IIDs of the 50\% points are topographically organized, which could then be imposed on the contralateral inferior colliculus via an ordered excitatory projection system. The finding that the $60 \mathrm{kHz}$ region of the lateral superior olive projects to the EI region of the $60 \mathrm{kHz}$ contour in the colliculus is consistent with this interpretation (Ross and Pollak, 1989). However, this scenario does not take into account the role of the dorsal nuclei of the lateral lemniscus, which also projects to the EI region of the $60 \mathrm{kHz}$ contour with stronger projections than those from the lateral superior olives (Ross and Pollak, 1989).

One of the implications of the present study is that the collicular map of IIDs is not simply a relayed version of a map established in the lateral superior olive, but rather is formed to a substantial degree in the colliculus by GABAergic innervation that likely originates in the contralateral dorsal nucleus of the lateral lemniscus and perhaps in the ipsilateral dorsal nucleus as well. The GABAergic innervation contributes to the establishment of the map and to the formation of receptive fields of the neurons in the mapped region in several ways. The first is by the creation of the EI property in some collicular cells through the convergence of excitatory and GABAergic inhibitory inputs. This not only establishes the binaural property of the cell, but in so doing establishes the IID of the cell's $50 \%$ point, and hence its receptive field border. A second way is seen in other cells where GABAergic inputs adjust their $50 \%$ point IIDs, and thus shift their receptive field borders. A third way occurs in yet other cells in which the maximum inhibition is increased, thereby enhancing the contrast on each side of the cell's receptive field border. Another implication of this study is that GABAergic inhibition shapes binaural facilitation in most collicular $\mathrm{EI} / \mathrm{f}$ cells. The effect of the facilitation is to shitt the maximum response rate of these cells in favor of sounds located along the midline.

Several of the effects of GABAergic inhibition, which include the shaping of response features not found in lower nuclei such as $\mathrm{EI} / \mathrm{f}$ properties, and the reinforcement of existing properties, as illustrated by the enhancement of maximum inhibition or the shifts in $50 \%$ point IIDs, are consistent with traditional ideas concerning the role of hierarchical information processing. The relevance of the $50 \%$ point shifts that we found may reside in the paucity of lateral superior olive units with positive $50 \%$ point IIDs that was recently reported by Covey and her colleagues for the mustache bat (Covey et al., 1991). This would suggest that only a portion of the $50 \%$ point IIDs present in the colliculus are established in the lateral superior olive and that the shaping of IID functions that produces neurons with positive $50 \%$ point IIDs is completed in the inferior colliculus. This modification may be important for creating the full range of $50 \%$ point IIDs, and hence the spatial receptive fields, required for the accurate representation of a sound source in the inferior 
colliculus. However, the de novo generation of EI cells is somewhat puzzling; we have to wonder why excitatory/inhibitory properties need to be created anew in the inferior colliculus, since excitatory/inhibitory cells are already established in the lateral superior olive. Of interest in this regard is that Müller and Scheich (1987) also report the construction of EI neurons in the avian forebrain. They suggest that monaural neurons may be better suited to accommodate the convergence of excitatory and inhibitory inputs required for complex sound analysis. Only after the cell acquires the appropriate response properties, a process presumably completed in the higher levels of the auditory system, is the neuron made binaural, thereby allowing it and others like it to participate simultaneously in the analysis of complex sound patterns and localization. This is an intriguing hypothesis that should be tested in future experiments concerned with processing at higher levels of the auditory system.

\section{References}

Adams JC (1980) Crossed and descending projections to the inferior colliculus. Neurosci Lett 19:1-5.

Adams JC, Mugniani E (1984) Dorsal nucleus of the lateral lemniscus: a nucleus of GABAergic projection neurons. Brain Res Bull 13:585590.

Adams JC, Wenthold RJ (1979) Distribution of putative amino acid transmitters choline acetyltransferase and glutamate decarboxylase in the inferior colliculus. Neuroscience 4:1947-1951.

Aitkin LM (1986) The auditory midbrain: structure and function in the central auditory pathway. Clifton, $\mathrm{NJ}$ : Humana.

Borman J (1988) Electrophysiology of $\mathrm{GABA}_{\mathrm{a}}$ and $\mathrm{GABA}_{\mathrm{B}}$ receptor subtypes. Trends Neurosci 11:112-116.

Boudreau JC, Tsuchitani C (1968) Binaural interaction in the cat superior olivary S-segment. J Neurophysiol 31:442-454.

Brugge JF, Anderson DJ, Aitkin LM (1970) Responses of neurons in the dorsal nucleus of the lateral lemniscus to binaural tonal stimuli. J Neurophysiol 33:441-458.

Brunso-Bechtold JK, Thompson GC, Masterton RB (1981) HRP study of the organization of auditory afferents ascending to the central nucleus of the inferior colliculus in the cat. J Comp Neurol 97:705-722.

Caird D, Klinke R (1983) Processing of binaural stimuli by cat superior olivary complex neurons. Exp Brain Res 52:385-399.

Cant N, Casseday JH (1986) Projections from the anteroventral cochlear nucleus to the lateral and medial superior olivary nuclei. J Comp Neurol 247:457-476.

Cant N, Morest DK (1984) The structural basis for stimulus coding in the cochlear nucleus of the cat. In: Hearing science (Berlin CI, ed), pp 37-342. San Diego: College Hill.

Caspary DM, Raza A, Lawhorn-Armour BA, Pippen J, Arneric SP (1990) Immunocytochemical and neurochemical evidence for age related loss of GABA in inferior colliculus: implications for neural presbycusis. J Neurosci 10:2363-2372.

Cooper JR, Bloom FE, Roth R (1982) The biochemical basis of neuropharmacology. New York: Oxford UP.

Covey E, Casseday JH (1991) The monaural nuclei of the lateral lemniscus in an echolocating bat: parallel pathways for analyzing temporal features of sound. J Neurosci 11:3456-3470.

Covey E, Vater M, Casseday JH (1991) Binaural properties of single units in the superior olivary complex of the mustached bat. J Neurophysiol 66:1080-1093.

Erulkar S (1972) Comparative aspects of sound localization. Physiol Rev 52:237-360.

Faingold CL, Gehlbach G, Caspary DM (1989) On the role of GABA as an inhibitory neurotransmitter in inferior colliculus neurons: iontophoretic studies. Brain Res 500:302-312.

Faingold CL, Boersma-Anderson CA, Caspary DM (1991) Involvement of GABA in acoustically-evoked inhibition in inferior colliculus. Hearing Res 52:201-216.

Frisina RD, O'Neill WE, Zettel ML (1989) Functional organization of mustached bat inferior colliculus: II. Connections of the FM2 region. J Comp Neurol 284:85-107.

Fujita I, Konishi M (1991) The role of GABAergic inhibition in pro- cessing of interaural time differences in the owl's auditory system. J Neurosci 11:722-739.

Fuzessery ZM, Pollak GD (1985) Determinants of sound location selectivity in bat inferior colliculus: a combined dichotic and freefield study. J Neurophysiol 54:757-781.

Fuzessery ZM, Wenstrup JJ, Pollak GD (1990) Determinants of horizontal sound location selectivity of binaurally excited neurons in an isofrequency region of the mustache bat inferior colliculus. J Neurophysiol $63: 1128-1147$.

Glendenning KK, Brunso-Bechtold JK, Thompson GC, Masterton RB (1981) Ascending auditory afferents to the nuclei of the lateral lemniscus. J Comp Neurol 197:673-703.

Glendenning KK, Baker BN, Hutson KA, Masterton RB (1992) Acoustic chiasm V: inhibition and excitation in the ipsilateral and contralateral projections of LSO. J Comp Neurol 319:100-122.

Goldberg JM, Brown PB (1968) Functional organization of the dog superior olivary complex: an anatomical and electrophysiological study. J Neurophysiol 31:639-656.

Goldberg JM, Brown PB (1969) Responses of binaural neurons of dog superior olivary complex to dichotic tonal stimuli: some physiological mechanisms of sound localization. J Neurophysiol 32:613-636.

Goldberg JM, Moore RY (1967) Ascending projections of the lateral lemniscus in the cat and monkey. J Comp Neurol 129:143-155.

Harnischfeger G, Neuweiler G, Schlegel P (1985) Interaural time and intensity coding in the superior olivary complex and inferior colliculus of the echolocating bat Molossus ater. J Neurophysiol 53:89-109.

Havey DC, Caspary DM (1980) A simple technique for constructing piggy back multibarrel microelectrodes. Electroencephalogr Clin Neurophysiol 48:249-251.

Hutson KA, Glendenning KK, Masterton RB (1987) Biochemical basis for the acoustic chiasm? Soc Neurosci Abstr 13:548.

Hutson KA, Glendenning KK, Masterton RB (1991) Acoustic chiasm IV: eight midbrain decussations of the auditory system in the cat. $\mathrm{J}$ Comp Neurol 312:105-131.

Irvine DR (1986) The auditory brainstem. In: Progress in sensory physiology, Vol 7 (Autrum H, Ottoson D, eds). Berlin: Springer.

Irvine DRF, Gago G (1990) Binaural interaction in high-frequency neurons in inferior colliculus of the cat: effects of variations in sound pressure level on sensitivity to interaural intensity differences. J Neurophysiol 63:570-591.

Kudo M (1981) Projections of the nuclei of the lateral lemniscus in the cat: an autoradiographic study. Brain Res 221:57-69.

Larue DT, Park TJ, Pollak GD, Winer JA (1991) Glycine and GABA immunostaining defines functional subregions of the lateral lemniscal nuclei in the mustache bat. Soc Neurosci Abstr 17:300.

Li L, Kelly JB (1992a) A reversible block of neural activity in DNLL alters binaural responses in contralateral inferior colliculus. Abstr Assoc Res Otolaryngol 15:62.

Li L, Kelly JB (1992b) Binaural responses in rat inferior colliculus following kainic acid lesions of the superior olive: interaural intensity difference functions. Hearing Res 61:73-85.

Markovitz NS, Pollak GD (1993) Anatomical connections and neurophysiological response properties of the mustache bat's dorsal nucleus of the lateral lemniscus. Abstr Assoc Res Otolaryngol, in press.

Mills AW (1972) Auditory localization. In: Foundations of modern auditory theory, Vol II (Tobias JV, ed), pp 303-348. New York: Academic.

Moore JK, Moore RY (1987) Glutamic acid decarboxylase-like immunoreactivity in brainstem auditory nuclei of the rat. J Comp Neurol 260:157-174.

Moore MJ, Caspary DM (1983) Strychnine blocks binaural inhibition in lateral superior olivary nucleus. J Neurosci 3:237-242.

Morest DK, Oliver DL (1984) The neuronal architecture of the inferior colliculus in the cat: defining the functional anatomy of the auditory midbrain. J Comp Neurol 222:209-236.

Mugniani E, Oertel WH (1985) An atlas of the distribution of GABAergic neurons and terminals in rat CNS as revealed by GAD immunocytochemistry. In: Handbook of chemical neuroanatomy, Vol 4, GABA and neuropeptides in the CNS, Pt I (Bjorklund A, Hokfelt T, eds), pp 436-608. Amsterdam: Elsevier.

Müller CM, Scheich H (1987) GABA mediates interaural inhibition in the avian auditory forebrain. Naturwissenschaften 74:602-604.

Oliver DL, Morest DK (1984) The central nucleus of the inferior colliculus in the cat. J Comp Neurol 222:237-264.

Oliver DL, Nuding SC, Beckius G (1988) Multiple cell types have 
GABA immunoreactivity in the inferior colliculus of the cat. Soc Neurosci Abstr 14:490.

Oliver DL, Kuwada S, Yin TCT, Haberly LB, Henkel CK (1991) Dendritic and axonal morphology of HRP-injected neurons in the inferior colliculus of the cat. J Comp Neurol 303:75-100.

Park T, Pollak GD, Winer JA, Larue DT (1991) Colocalization of inhibitory transmitters and HRP in projections of the mustache bat's auditory brainstem: projections from the LSO to the inferior colliculus. Abstr Assoc Res Otolaryngol 14:89.

Pollak GD (1992) Adaptations of basic structures and mechanisms in the cochlea and central auditory pathway of the mustache bat. In: Evolutionary biology of the auditory system (Popper A, Fay R, Webster D, eds), pp 751-778. Berlin: Springer.

Pollak GD, Casseday JH (1989) The neural basis of echolocation in bats. Berlin: Springer.

Pollak GD, Park TJ (1993) The effects of GABAergic inhibition on monaural response properties of neurons in the mustache bat's inferior colliculus. Hearing Res, in press.

Pollak GD, Winer JA (1989) Glycinergic and GABAergic auditory brainstem neurons and axons in the mustache bat. Soc Neurosci Abstr 15:1115.

Pollak GD, Wenstrup JJ, Fuzessery ZM (1986) Auditory processing in the mustache bat's inferior colliculus. Trends Neurosci 9:556-561.

Pollak GD, Park TJ, Larue DT, Winer JA (1992) The role inhibitory circuits play in shaping receptive fields of neurons in the mustache bat's inferior colliculus. In: Nervous Systems: Principles of design and function (Singh RN, ed), in press. New Delhi: Wiley Eastern.

Purves RD (1981) Microelectrode methods for intracellular recording and iontophoresis. New York: Academic.

Roberts RC, Ribak CE (1987a) GABAergic neurons and axon terminals in the brainstem auditory nuclei of the gerbil. J Comp Neurol 258:267-280.

Roberts RC, Ribak CE (1987b) An electron microscopic study of GABAergic neurons and terminals in the central nucleus of the inferior colliculus. J Neurocytol 16:333-345.

Rockel AS, Jones EG (1973a) The neuronal organization of the inferior colliculus of the adult cat. I. The central nucleus. J Comp Neurol 147: 11-60.

Rockel AS, Jones EG (1973b) The fine structure of the central nucleus of the inferior colliculus of the cat. J Comp Neurol 147:61-92.

Ross LS, Pollak GD (1989) Differential projections to aural regions in the $60 \mathrm{kHz}$ isofrequency contour of the mustache bat's inferior colliculus. J Neurosci 9:2819-2834.

Ross LS, Pollak GD, Zook JM (1988) Origin of ascending projections to an isofrequency region of the mustache bat's inferior colliculus. J Comp Neurol 270:488-505.

Roth GL, Aitkin LM, Andersen RA, Merzenich MM (1978) Some features of the spatial organization of the central nucleus of the inferior colliculus of the cat. J Comp Neurol 182:661-680.

Saint Marie RL, Baker RA (1990) Neurotransmitter specific uptake and retrograde transport of $\left[{ }^{3} \mathrm{H}\right]$ glycine from the inferior colliculus by ipsilateral projections of the superior olivary complex and nuclei of the lateral lemniscus. Brain Res 524:244-253.

Saint Marie RL, Ostapoff ME, Morest DK, Wenthold RI (1989) Glycine-immunoreactive projection of the cat lateral superior olive: possible role in midbrain dominance. J Comp Neurol 279:382-396.

Saldana E, Merchan MA (1992) Intrinsic and commissural connections of the rat inferior colliculus. J Comp Neurol 319:417-437.
Sally SL, Kelly JB (1992) Effects of superior olivary complex lesions on binaural responses in rat inferior colliculus. Brain Res 572:5-18.

Sanes DH, Rubel EW (1988) The ontogeny of inhibition and excitation in the gerbil lateral superior olive. $J$ Ncurosci 8:682-700.

Schuller G, Radtke-Schuller S, Betz M (1986) A stereotaxic method for small animals using experimentally determined reference profiles. J Neurosci Methods 18:339-350.

Semple MN, Aitkin LM (1979) Representation of sound frequency and laterality by units in the central nucleus of the cat's inferior colliculus. J Neurophysiol 42:1626-1639.

Semple MN, Kitzes LM (1987) Binaural processing of sound pressure level in the inferior colliculus. J Neurophysiol 57:1130-1147.

Shneiderman A, Henkel CK (1987) Banding of lateral superior olivary nucleus afferents in the inferior colliculus: a possible substrate for sensory integration. J Comp Neurol 266:519-534.

Shneiderman A, Oliver DL (1989) EM autoradiographic study of the projections from the dorsal nucleus of he lateral lemniscus: a possible source of inhibitory inputs to the inferior colliculus. J Comp Neurol 286:28-47.

Shneiderman A, Oliver DL, Henkel CK (1988) The connections of the dorsal nucleus of the lateral lemniscus. An inhibitory parallel pathway in the ascending auditory system? J Comp Neurol 276:188208.

Thompson GC, Cortez AM, Lam DM-K (1985) Localization of GABA immunoreactivity in the auditory brainstem of guinea pigs. Brain Res 339:119-122.

Vater M, Kössl M, Horn AKE (1992) GAD- and GABA-immunoreactivity in the ascending auditory pathway of horseshoe and mustache bats. J Comp Neurol 385:183-206.

Wenstrup JJ, Ross LS, Pollak GD (1985) A functional organization of binaural responses in the inferior colliculus. Hearing Res 17:191195.

Wenstrup JJ, Ross LS, Pollak GD (1986) Binaural response organization within a frequency-band representation of the inferior colliculus: implications for sound localization. J Neurosci 6:962-973.

Wenstrup JJ, Fuzessery ZM, Pollak GD (1988a) Binaural neurons in the mustache bat's inferior colliculus: I. Responses of $60 \mathrm{kHz}$ E-I units to dichotic sound stimulation. J Neurophysiol 60:1369-1383.

Wenstrup JJ, Fuzessery ZM, Pollak GD (1988b) Binaural neurons in the mustache bat's inferior colliculus: II. Determinants of spatial responses among $60 \mathrm{kHz}$ E-I units. J Neurophysiol 60:1384-1404.

Yang L, Pollak GD, Resler C (1992) GABAergic circuits sharpen tuning curves and modify response properties in the mustache bat's inferior colliculus. J Neurophysiol 68:1760-1774.

Yin TCT, Chan CK (1990) Interaural time sensitivity in the medial superior olive of cat. J Ncurophysiol 64:465-488.

Zook JM, Casseday JH (1982) Origin of ascending projections to inferior colliculus in the mustache bat Pteronotus parnellii. $\mathrm{J}$ Comp Neurol 207:14-28.

Zook JM, Casseday JH (1987) Convergence of ascending pathways at the inferior colliculus in the mustache bat Pteronotus parnellii. J Comp Neurol 261:347-361

Zook JM, Winer JA, Pollak GD, Bodenhamer RD (1985) Topology of the central nucleus of the mustache bat's inferior colliculus: correlation of single unit properties and neuronal architecture. J Comp Neurol 231:530-546. 